Article

\title{
Evaluation of B-cell kinetics after acellular pertussis vaccina- tion in four cohorts of different age and priming background
}

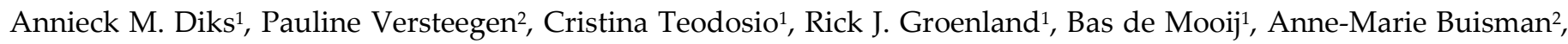
Alba Torres-Valle3,4, Martin Perez-Andres,3,4, Alberto Orfao ${ }^{3,4}$, Guy A.M. Berbers², Jacques J.M. van Dongen ${ }^{1}$, Magdalena A. Berkowska ${ }^{1}$ on behalf of the IMI-2 PERISCOPE Consortium

1 Department of Immunology, Leiden University Medical Center, Albinusdreef 2, 2333 ZA, Leiden, The Netherlands; A.M.Diks@lumc.nl, C.I.Teodosio@lumc.nl, R.J.Groenland@lumc.nl, demooij.bas@gmail.com, L.J.M.van Dongen@lumc.nl, M.A.Berkowska@lumc.nl

2 Center for Infectious Disease Control, National Institute of Public Health and the Environment, Antonie van Leeuwenhoeklaan 9, 3721 MA Bilthoven, The Netherlands; pauline.versteegen@rivm.nl, annemarie.buisman@rivm.nl, guy.berbers@rivm.nl

3 Cancer Research Centre (IBMCC, USAL-CSIC; CIBERONC CB16/12/00400), Institute for Biomedical Research of Salamanca (IBSAL), Salamanca, Spain

4 Department of Medicine and Cytometry Service (NUCLEUS Research Support Platform), University of Salamanca (USAL), Salamanca, Spain; albatorresvalle@usal.es, mmmar@usal.es, orfao@usal.es

* Correspondence: I.J.M.van Dongen@lumc.nl

\begin{abstract}
Pertussis is a vaccine-preventable disease caused by the bacterium Bordetella pertussis. Over the past years, the incidence and mortality of pertussis increased significantly. A possible cause is the switch from whole cell to acellular pertussis vaccines, although other factors may also contribute. To develop future vaccines and improve current vaccination strategies, it is critical to understand factors influencing the generation of immunological memory. We applied high-dimensional flow cytometry to investigate changes in B cells in individuals of different ages and distinct priming backgrounds upon administration of an acellular pertussis booster vaccine. These findings were correlated to vaccine-specific plasma cells and serum Ig levels. Expansion and maturation of plasma cells 7 days post-vaccination was the most prominent cellular change in all age groups, and was most pronounced for more mature IgG1+ plasma cells. Cellular responses were stronger in individuals primed with whole cell vaccine than in individuals primed with acellular vaccine. Moreover, IgG1+ plasma cell expansion weakly correlated with Prn- and PT- specific serum IgG levels. Our study points at plasma cells as a potential early cellular marker of an immune response and contributes to understanding differences in immune responses between age groups and priming backgrounds.
\end{abstract}

Keywords: Tdap, flow cytometry, acellular pertussis vaccine, whole cell pertussis vaccine, plasma cells

\section{Introduction}

Pertussis is a vaccine-preventable respiratory disease caused by the bacterium Bordetella pertussis (Bp). Since the introduction of the first pertussis vaccines in 1940/50 containing whole inactivated bacteria (whole cell pertussis; $\mathrm{wP}$ ), the incidence and mortality due to pertussis have dramatically decreased [1]. However, the $\mathrm{wP}_{\mathrm{P}}$ vaccine itself has a relatively high reactogenicity profile [2,3]. Therefore, from early 1980s onwards, many (developed) countries started to replace the $\mathrm{wP}$ vaccine by an acellular pertussis $(\mathrm{aP})$ vaccine which had a more favorable reactogenicity profile $[3,4]$. In the Netherlands, this 
change took place on January 1st, 2005. Acellular variants contain purified Bp components, such as pertussis toxoid (PT), filamentous hemagglutinin (FHA), pertactin (Prn), Fimbriae 2 and 3 (Fim2/3). In the Netherlands, the combined DTaP-IPV-Hib-HepB vaccine (providing protection against diphtheria, tetanus, pertussis, polio, Haemophilus influenzae type $b$ (Hib) and hepatitis B) is used for primary vaccination, where boosters at later age are often Tdap vaccines [5].

Immune surveillance data showed that despite high vaccination coverage in many countries, there has been an increase of pertussis in the past decennia [6, 7]. This increase is not only seen in aP-using countries, but it has also been reported in countries where primarily $\mathrm{wP}$ is used $[6,8]$. Several possible explanations for this increase have been proposed. First of all, improved awareness, surveillance and diagnostics may increase the detection rate [9]. Furthermore, several new Bp strains have been identified, i.e. that lack antigens present in the aP vaccine (such as FHA or Prn deficient strains), or PtxP3 strains that have adapted to suppress host immunity by producing higher levels of PT [10-13]. Lastly, there may be increased carriership within the population as well as faster waning of protective immunity in aP-primed individuals. Initial studies comparing efficacy of aP vs $\mathrm{wP}$ vaccines showed a similar short-term protection [14, 15]. However, later long-term studies showed that protection lasted shorter when using aP vaccines [16-19]. Also baboon models have shown that aP-induced immunity does not prevent transmission, immunity induced by $\mathrm{wP}$ vaccines leads to a faster clearance of bacteria, and immunity generated by infection prevents colonization [20]. These combined data point at the need for mucosal immunity to prevent or reduce colonization and carriership.

An improved vaccine, immunization program, and/or route of administration seem necessary to combat pertussis. This implies a need to first understand the mechanism underlying protection induced by aP and $\mathrm{wP}$ vaccines (their differences and similarities). So far, no true correlate of protection (neither serological nor cellular) has been established for pertussis, and this would greatly aid evaluation of newly developed vaccines. This is one of the pillars of the Innovative Medicines Initiative (IMI)2 PERISCOPE consortium (PERtussIS COrrelates of Protection Europe), which aims to increase the scientific understanding of pertussis-related immunity in humans, identify new biomarkers of protection and to generate technology and infrastructure for the future development of improved pertussis vaccines [21].

Several (recent) studies both within and outside the IMI2 PERISCOPE consortium have shown that initial priming against pertussis ( $\mathrm{aP}$ or $\mathrm{wP}$ vaccine) influences protection against disease as well as the immune response to (future) booster vaccinations [16, 18, 22-25]. For example, Hendrikx et al found that in aP-primed children, Ag-specific IgG4 serum levels were higher compared to $\mathrm{wP}$-primed children [23]. Furthermore, Da Silva et al showed that -even after receiving aP booster vaccinations- initial priming ( $\mathrm{wP}$ or aP vaccine) determined the antigen-specific CD4 T-cell response [24]. Similarly, Lambert et al showed that $\mathrm{CD} 4 \mathrm{~T}$ cells isolated from recently aP-boostered individuals could be separated in a PCA view based on priming background, where an aP priming background resulted in a more Th2-related response as compared to a wP priming background [22].

As neither vaccine-induced nor infection-induced immunity leads to life-long protection against pertussis, the use of booster vaccinations later in life is a topic relevant for public health, as people with waned immunity can become carriers and thereby a source of transmission. Moreover, older adults can be more vulnerable to severe disease outcomes [26]. Several studies have shown that aP boosters are effective and well-tolerated in (older) adults [27, 28]. Recently, Versteegen et al investigated the specific serological response to an aP booster vaccination in four cohorts of different ages and priming backgrounds in the Netherlands, Finland and the UK (IMI2 PERISCOPE study acronym: BERT; Booster pertussis vaccination study) [29]. Here, they found all age cohorts showed a good response upon booster vaccination, with only limited differences between the different age cohorts for the Bp-specific IgG levels. However, Ag-specific serum IgA (both pre- and post-vaccination) increased with age, likely caused by over-time (mild) exposures to Bp. 
Previous studies on influenza have shown that up to $80 \%$ of the circulating $\operatorname{IgG}$ plasma cells 7 days after vaccination can be vaccine-specific [30,31]. This, combined with the low numbers of circulating plasma cells at baseline (median counts $<5$ cells/ul [32]), implies that the plasma cell system is a relatively 'clean' system to monitor. Thus, flow cytometry may serve as a faster and less laborious approach to study vaccination-elicited plasma cells than typically Ag-specific approaches such as ELISpot. Recently, our team used high-dimensional flow cytometry to investigate over-time cellular kinetics in 10 healthy (wP-primed) adults upon aP vaccination. There, we were able to demonstrate a clear expansion and maturation of plasma cells (especially IgG1+) and a strong correlation between IgG1+ memory B-cell expansion and the magnitude of the Ag-specific IgG serum response [33]. Here, we extended our exploratory studies by the analysis of participants of different ages and different priming background after receiving an aP booster (BoostrixIPV, GlaxoSmithKline (GSK), Wavre, Belgium). We included 48 individuals enrolled in the Dutch cohort used in the IMI2 PERISCOPE- BERT study (periscope-project.eu/patients/study-2-bert/) at pre-defined time points, with the primary objective to describe the kinetics of circulating B-cell populations in four cohorts of different ages and with different priming backgrounds. This may lead to new insights on the impact of priming at infancy with aP or $\mathrm{wP}$ vaccines on future immune responses.

\section{Materials and Methods}

\subsection{Study design and sample collection}

This study comprises one of the exploratory objectives of the Dutch 'BERT study', which was initiated by the IMI2 PERISCOPE consortium. It was approved by Medical Research Ethics Committees United (MEC-U, NL60807.100.17-R17.039) and registered at the EU Clinical trial registry (EudraCT number 2016-003678-42). To be eligible for this study, participants had to (1) be generally healthy, (2) have no recent evidence of serious disease, i.e. requiring the use of immunosuppressive or immunomodulating medication, within the 3 months prior to inclusion, (3) received all regular vaccines according to Dutch National Immunization Program (www.rivm.nl/en/national-immunisation-programme) as appropriate for their age. An extensive description of the cohort and exclusion criteria have recently been published by Versteegen and colleagues [29]. A fraction of the participants of this aP vaccination study was subjected to additional exploratory analysis, such as mass cytometry, evaluation of mucosal antibodies, NGS or in-depth flow cytometry. The exploratory sub-study monitoring the fluctuations in circulating B-cell subsets after vaccination is discussed in this manuscript. Here, 48 individuals were selected from 4 cohorts of different age and distinct priming background at infancy (children, 7-10 y/o, aPprimed; adolescents, 11-15 y/o, aP or wP-primed; young adults, 20-34 y/o, wP-primed; older adults 60-70 y/o, in whom vaccination history was unknown (presumably: wPprimed or not vaccinated)).

The study was conducted by the Spaarne Academy (Spaarne Hospital, Hoofddorp, the Netherlands). Written informed consent was obtained at the start of the study. Participants were vaccinated intramuscularly with the Boostrix-IPV vaccine after their first blood donation (baseline). Boostrix-IPV is a reduced-antigen Tdap-IPV booster vaccine, which contains diphtheria toxoid (Diph) ( $\geq 2.5$ Limit of flocculation (Lf)), tetanus toxoid (Tet) ( $\geq 5 \mathrm{Lf})$, three Bordetella pertussis proteins, being PT $(8 \mu \mathrm{g})$, FHA $(8 \mu \mathrm{g})$, Prn $(2.5 \mu \mathrm{g})$ and inactivated poliovirus (Mahoney strain; 40 D-Antigen units (DU), MEF-1 strain; 8 DU, Saukett strain; 32 DU) and aluminum hydroxide as adjuvant [34]. Peripheral blood samples were collected in blood collection tubes using heparin as anticoagulant and in serum collection tubes at baseline, day 7 and 28 after vaccination. An additional peripheral blood sample was taken at day 14 in participants aged 20-34 and aged 60-70. Individuals were excluded and replaced by a new participant if a blood sample at day 0 or 28 could not be obtained. 


\subsection{Evaluation of antigen-specific immunoglobulin levels in serum}

Serological analysis was performed in all collected samples. Levels of IgG directed against Tet, PT, FHA, Prn, and Fim2/3, and levels of IgA directed against PT, FHA, Prn and Fim $2 / 3$ were determined by multiplex immunoassay (MIA) at the Dutch National Institute for Public Health and the Environment (RIVM, The Netherlands) [35]. The serum antibody responses raised against Bp-antigens during the PERISCOPE-BERT study have been extensively discussed by Versteegen and colleagues [29].

Detection of vaccine-specific antibody-producing plasma cells and memory B cells

Analysis of numbers of IgG and IgA producing plasma cells and memory B cells was performed in majority of the samples included in this study. B cells producing IgG directed against PT, FHA, Prn and Tet, and B cells producing IgA direct against PT, FHA and Prn were measured using an Enzyme-Linked Immunospot (ELISpot) assay at the RIVM. This procedure has been described previously [36]. In short, peripheral blood mononuclear cells (PBMCs) were isolated using a density gradient. For antibody producing plasma cells, PBMCs at day 7 post-vaccination were directly transferred to Ag-coated ELISpot filter plates (duplicates). For the detection of vaccine-specific memory B cells, PBMCs collected at day 0 and day 28 were collected and stored at $-135^{\circ} \mathrm{C}$. Thawed PBMCs were stimulated for 5 days using a culture medium containing CPG, IL-2 and IL-10. Next, cells were transferred to Ag-coated plates (duplicates). Numbers of Ag-specific antibodyproducing cells - appearing as spots- were measured using an ImmunoSpot S6 Ultra-V analyzer (Cellular Technology Limited, Cleveland, $\mathrm{OH}$ ). Uncoated wells filled with PBS served as negative control and were used to subtract background signal. Wells with a signal below the limit of quantification were set at 0.1 cell/105 PBMCs. Cumulative IgG and IgA spot counts for all antigens measured were used for analyses.

\subsection{Longitudinal flow cytometric analysis of circulating B-cell subsets}

All peripheral blood samples were subjected to high-throughput flow cytometric immunophenotyping of the B-cell compartment. Here, we used the recently developed BIGH-tube: the B-cell and plasma cell tube (BIGH) allows identification of $>100$ populations of $\mathrm{B}$ - and plasma cells distinguished based on their maturation stage and expressed Ig subclasses [32,37] (Antibody panel and phenotypic description of the identified B-cell subsets: Supplemental Table 1 and 2).

Samples were processed according to the bulk lysis protocol using $10 \times 106$ cells followed by intracellular staining as described before [33] (protocols available on www.EuroFlow.org), with the addition of membrane staining with CD45-AlexaFluor700.

In short, based on the white blood cell count (as determined by an automated hematological analyzer (Sysmex XP-300, Sysmex Europe GmbH, Norderstedt, Germany)), one or multiple tubes were filled with up to $2 \mathrm{~mL}$ of blood, after which ammonium chloride was added up to a total volume of $50 \mathrm{~mL}$. After a $15 \mathrm{~min}$ incubation at room temperature on a roller bank to lyse non-nucleated red blood cells, cells were washed, counted on a Sysmex XP-300 and pooled to a total of 10x106 cells. Next, cells were stained with an antibody cocktail directed against surface markers for $30 \mathrm{~min}$ in the dark with the BIGH panel (Supplemental Table 1). This was followed by a cytoplasmic staining for intracellular Igs using the Fix \& Perm reagent kit (Nordic MUbio, Susteren, The Netherlands) according to manufacturers' protocol. Finally, samples were washed and resuspended in PBS for immediate acquisition (or stored for max $\sim 3 \mathrm{~h}$ at $4^{\circ} \mathrm{C}$ ).

For precise enumeration of cell numbers, we used Perfect-Count Microspheres ${ }^{\mathrm{TM}}$ (Cytognos) according to the EuroFlow SOP (protocol available on www.EuroFlow.org). In short, exactly 50ul of well-mixed Perfect-Count Microspheres ${ }^{\mathrm{TM}}$ were added to exactly 50ul of peripheral blood. Then, antibodies directed against CD19, CD3 and CD45 were added and the sample was incubated for $30 \mathrm{~min}$ in the dark. Next, 500uL of $\mathrm{NH} 4 \mathrm{Cl}$ was added and after 10 minutes incubation samples were ready for immediate acquisition. Using this tube, we could identify and quantify total leukocytes and lymphocytes, B-, Tand NK cells in each sample. All samples were acquired at the Flow cytometry Core Facility of LUMC, using a BD FACS LSR Fortessa 4L (BD Biosciences, San Jose, CA, USA) 
or a BD FACS LSR Fortessa X-20 flow cytometer (BD Biosciences), which were calibrated daily according to EuroFlow guidelines, as previously described [38, 39].

\subsection{Data analysis and statistics}

To ensure objective data analysis and minimize operator-induced variability, all data were analyzed using the automated gating and identification (AGI) module of the Infinicyt software (Infinicyt ${ }^{\mathrm{TM}}$ Software v2.0, Cytognos). This AGI module makes use of clustering algorithms and comparison with fully annotated reference flow cytometry (FCS) data files of healthy individuals to assign clusters of events to a population [40] . Importantly, when there was no perfect fit for a cluster of events, this was marked as a 'check' population and the software indicated to which populations this cluster may correspond. These check events were assigned manually according to the proposed gating strategies for the BIGH panel (Supplemental Table 2) [32, 37].

For visualization and statistical analysis, the GraphPad Prism 8.1.1 software (GraphPad, San Diego, CA, USA) was used. To test longitudinal data within a cohort, the Wilcoxon signed-rank test for paired samples was used. Correlations were determined using Spearman's Ranking Correlation (correlation coefficients of $<0.6$ or - in case of negative correlation >- 0.6 were considered weak correlations). Finally, to compare differences between the four cohorts, the Kruskal-Wallis approach was used, followed by Dunn's test, and, as only BU and BV samples were measured at day 14, the Mann-Whitney test was used instead of Kruskal-Wallis at day 14. To correct for multiple testing, tests were followed by Bonferroni correction when appropriate.

\section{Results}

\subsection{Study cohorts}

All subjects enrolled in the study between October 2017 and March 2018. In total, 12 children (age: 7-10, aP-primed, m/f ratio: 6/6), 12 adolescents (age: 11-15, 7 individuals wPprimed, $\mathrm{m} / \mathrm{f}$ ratio: 2/5, 5 individuals aP-primed, $\mathrm{m} / \mathrm{f}$ ratio: $4 / 1$ ), 12 young adults (age 2034, wP-primed, $\mathrm{m} / \mathrm{f}$ ratio: $7 / 5$ ) and 12 older adults (age 60-70, presumably wP-primed or not vaccinated, $\mathrm{m} / \mathrm{f}$ ratio: $4 / 7$ ) completed this study (as part of the PERISCOPE BERT study). Three additional children, who were initially enrolled, did not participate beyond the first visit and were replaced by three new participants. From all acquired samples, two baseline B-cell samples were lost due to technical problems (one child and one young adult). Finally, one older adult was excluded due to (potentially) clonal expansion of B cells and replaced by a new participant.

For most participants the leukocyte, lymphocyte, T-cell, B-cell and NK-cell counts at baseline were within the normal age-matched range (Supplemental Table 3, Table 1), or, in case of minor deviations, fell into the normal range at later time points [41, 42]. Leukocytes, lymphocytes and T cells remained mostly stable over the time of analysis. Although NK-cell numbers showed a minor decrease at day 28 , this was most likely not related to the vaccination response (day 0 vs $28, p \leq 0.01$ and day 7 vs $28, p \leq 0.05$, Supplemental Figure 1). There were no statistically significant differences in absolute leukocyte, lymphocyte, T-cell and NK-cell counts at baseline in-between age cohorts. Thus, regarding the numbers of leukocytes, lymphocytes, B cells, T cells and NK cells, our donors were healthy representatives of the general population. 
Table 1. Baseline distribution of normal B-cell and plasma cell subsets (cells/ $\mu$ l) in each age cohort. Ages of the cohorts of which reference values were used: children 5-9 y/o, adolescents 10-17 y/o, young adults 18-39 y/o, older adults 60-79 y/o. The reference values as indicated in this table were selected from the study performed by Blanco et al. [32] In the before-mentioned study, reference values for B-cell subsets are provided for all age ranges (from cord blood until older adults $>80 \mathrm{y} / \mathrm{o}$ ). When referring to the reference values indicated here, please refer to the original source data.

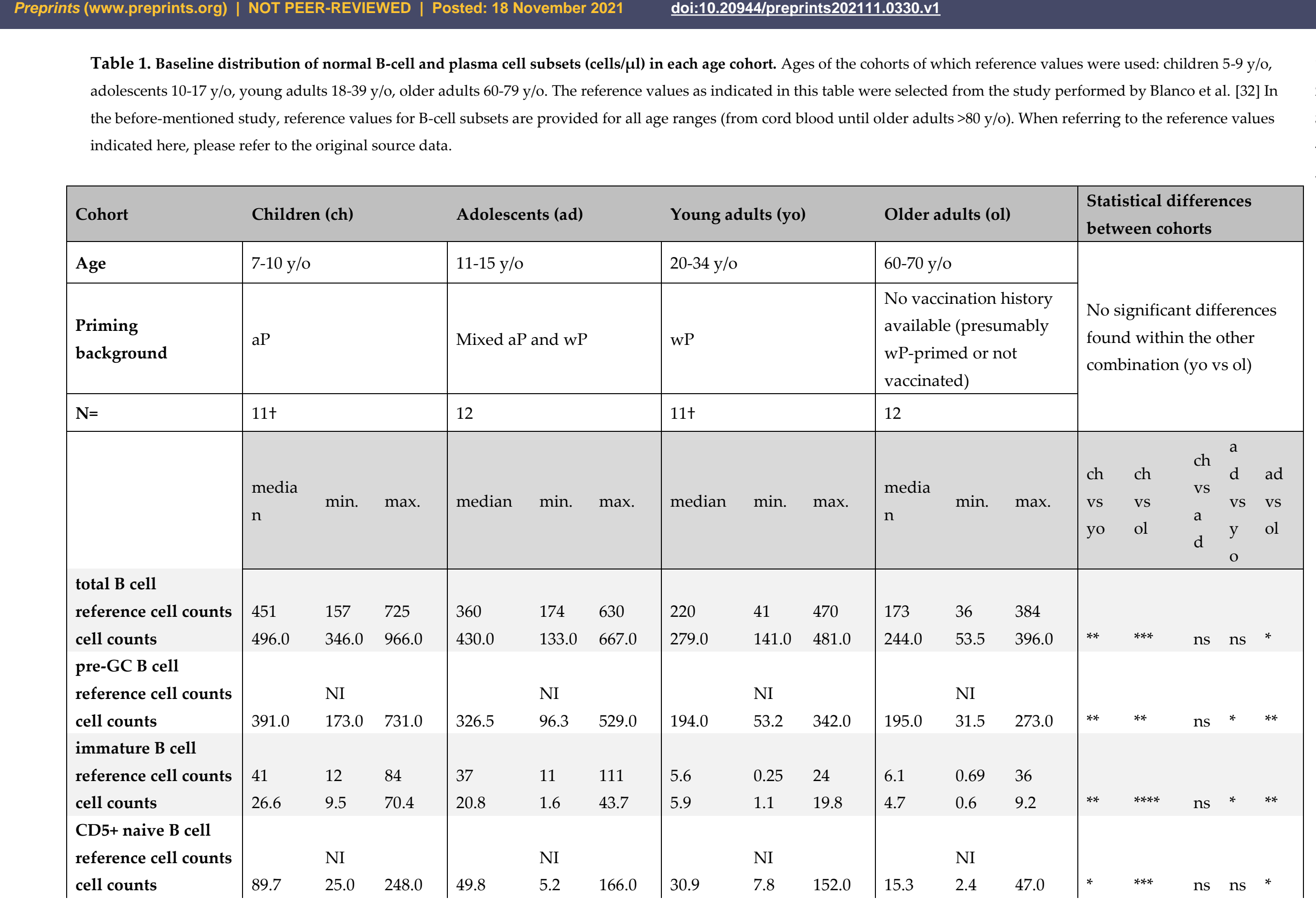




\begin{tabular}{|c|c|c|c|c|c|c|c|c|c|c|c|c|c|c|c|c|c|}
\hline $\begin{array}{l}\text { naive } B \text { cells } \\
\text { reference cell counts } \\
\text { cell counts }\end{array}$ & $\begin{array}{l}265 \\
260.0\end{array}$ & $\begin{array}{l}68 \\
124.0\end{array}$ & $\begin{array}{l}505 \\
483.0\end{array}$ & $\begin{array}{l}189 \\
238.5\end{array}$ & $\begin{array}{l}75 \\
89.4\end{array}$ & $\begin{array}{l}401 \\
335.0\end{array}$ & $\begin{array}{l}111 \\
160.0\end{array}$ & $\begin{array}{l}13 \\
44.0\end{array}$ & $\begin{array}{l}288 \\
186.0\end{array}$ & $\begin{array}{l}109 \\
150.0\end{array}$ & $\begin{array}{l}20 \\
24.9\end{array}$ & $\begin{array}{l}280 \\
250.0\end{array}$ & $* *$ & * & ns & ns & $*$ \\
\hline $\begin{array}{l}\text { memory B cell } \\
\text { reference cell counts } \\
\text { cell counts }\end{array}$ & $\begin{array}{l}123 \\
160.0\end{array}$ & $\begin{array}{l}64 \\
76.1\end{array}$ & $\begin{array}{l}282 \\
252.0\end{array}$ & $\begin{array}{l}68 \\
96.2\end{array}$ & $\begin{array}{l}31 \\
33.6\end{array}$ & $\begin{array}{l}160 \\
193.0\end{array}$ & $\begin{array}{l}91 \\
85.7\end{array}$ & $\begin{array}{l}23 \\
31.3\end{array}$ & $\begin{array}{l}221 \\
282.0\end{array}$ & $\begin{array}{l}56 \\
63.8\end{array}$ & $\begin{array}{l}13 \\
21.1\end{array}$ & $\begin{array}{l}128 \\
171.0\end{array}$ & ns & $* *$ & ns & ns & ns \\
\hline $\begin{array}{l}\text { IgMD+ memory } \\
\text { cells } \\
\text { reference cell counts } \\
\text { cell counts }\end{array}$ & $\begin{array}{l}54 \\
65.7\end{array}$ & $\begin{array}{l}23 \\
30.7\end{array}$ & $\begin{array}{l}147 \\
129.0\end{array}$ & $\begin{array}{l}29 \\
48.8\end{array}$ & $\begin{array}{l}17 \\
16.0\end{array}$ & $\begin{array}{l}78 \\
141.0\end{array}$ & $\begin{array}{l}38 \\
37.4\end{array}$ & $\begin{array}{l}7.9 \\
10.0\end{array}$ & $\begin{array}{l}122 \\
121.0\end{array}$ & $\begin{array}{l}27 \\
20.8\end{array}$ & $\begin{array}{l}7.4 \\
8.6\end{array}$ & $\begin{array}{l}72 \\
93.2\end{array}$ & $*$ & $* * * *$ & ns & ns & ns \\
\hline $\begin{array}{l}\text { IgG1+ memory cells } \\
\text { reference cell counts } \\
\text { cell counts }\end{array}$ & $\begin{array}{l}30 \\
47.8\end{array}$ & $\begin{array}{l}12 \\
15.2\end{array}$ & $\begin{array}{l}86 \\
81.7\end{array}$ & $\begin{array}{l}18 \\
17.3\end{array}$ & $\begin{array}{l}7 \\
6.8\end{array}$ & $\begin{array}{l}42 \\
44.7\end{array}$ & $\begin{array}{l}18 \\
13.2\end{array}$ & $\begin{array}{l}3.2 \\
5.4\end{array}$ & $\begin{array}{l}40 \\
72.5\end{array}$ & $\begin{array}{l}9.1 \\
16.5\end{array}$ & $\begin{array}{l}1.3 \\
2.8\end{array}$ & $\begin{array}{l}22 \\
27.8\end{array}$ & * & $* * * *$ & ns & ns & $* *$ \\
\hline $\begin{array}{l}\text { IgG2+ memory cells } \\
\text { reference cell counts } \\
\text { cell counts }\end{array}$ & $\begin{array}{l}4.4 \\
3.8\end{array}$ & $\begin{array}{l}0.7 \\
1.6\end{array}$ & $\begin{array}{l}15 \\
10.3\end{array}$ & $\begin{array}{l}3.0 \\
2.8\end{array}$ & $\begin{array}{l}0.7 \\
1.4\end{array}$ & $\begin{array}{l}10 \\
4.4\end{array}$ & $\begin{array}{l}5.9 \\
3.1\end{array}$ & $\begin{array}{l}1.6 \\
1.1\end{array}$ & $\begin{array}{l}30 \\
12.3\end{array}$ & $\begin{array}{l}3.6 \\
2.8\end{array}$ & $\begin{array}{l}1.0 \\
0.6\end{array}$ & $\begin{array}{l}11 \\
13.4\end{array}$ & * & $* * *$ & ns & ns & ns \\
\hline $\begin{array}{l}\text { IgG3+ memory cells } \\
\text { reference cell counts } \\
\text { cell counts }\end{array}$ & $\begin{array}{l}7.4 \\
7.9\end{array}$ & $\begin{array}{l}2.4 \\
3.2\end{array}$ & $\begin{array}{l}16 \\
13.0\end{array}$ & $\begin{array}{l}3.0 \\
3.1\end{array}$ & $\begin{array}{l}1.1 \\
0.6\end{array}$ & $\begin{array}{l}8.3 \\
7.1\end{array}$ & $\begin{array}{l}3.0 \\
1.8\end{array}$ & $\begin{array}{l}0.5 \\
0.8\end{array}$ & $\begin{array}{l}8.4 \\
6.4\end{array}$ & $\begin{array}{l}2.3 \\
2.1\end{array}$ & $\begin{array}{l}0.4 \\
0.5\end{array}$ & $\begin{array}{l}8.1 \\
7.4\end{array}$ & * & $* *$ & ns & ns & ns \\
\hline $\begin{array}{l}\text { IgG4+ memory cells } \\
\text { reference cell counts } \\
\text { cell counts }\end{array}$ & $\begin{array}{l}0.4 \\
0.2\end{array}$ & $\begin{array}{l}<0.01 \\
<0.05\end{array}$ & $\begin{array}{l}2.0 \\
2.2\end{array}$ & $\begin{array}{l}0.2 \\
0.3\end{array}$ & $\begin{array}{l}<0.01 \\
<0.05\end{array}$ & $\begin{array}{l}2.9 \\
1.0\end{array}$ & $\begin{array}{l}0.4 \\
0.5\end{array}$ & $\begin{array}{l}<0.01 \\
0.1\end{array}$ & $\begin{array}{l}2.4 \\
6.1\end{array}$ & $\begin{array}{l}0.4 \\
0.3\end{array}$ & $\begin{array}{l}<0.01 \\
0.1\end{array}$ & $\begin{array}{l}2.1 \\
1.2\end{array}$ & ns & $* * *$ & ns & ns & ns \\
\hline $\begin{array}{l}\text { IgA1+ memory cells } \\
\text { reference cell counts } \\
\text { cell counts }\end{array}$ & $\begin{array}{l}12 \\
16.3\end{array}$ & $\begin{array}{l}4.5 \\
6.4\end{array}$ & $\begin{array}{l}24 \\
34.7\end{array}$ & $\begin{array}{l}9.0 \\
11.4\end{array}$ & $\begin{array}{l}2.9 \\
4.4\end{array}$ & $\begin{array}{l}21 \\
14.7\end{array}$ & $\begin{array}{l}11 \\
8.0\end{array}$ & $\begin{array}{l}2.1 \\
3.8\end{array}$ & $\begin{array}{l}43 \\
42.4\end{array}$ & $\begin{array}{l}6.2 \\
11.2\end{array}$ & $\begin{array}{l}2.2 \\
4.2\end{array}$ & $\begin{array}{l}22 \\
30.4\end{array}$ & ns & ns & ns & ns & ns \\
\hline $\begin{array}{l}\text { IgA2+ memory cells } \\
\text { reference cell counts } \\
\text { cell counts }\end{array}$ & $\begin{array}{l}3.2 \\
4.8\end{array}$ & $\begin{array}{l}1.0 \\
1.4\end{array}$ & $\begin{array}{l}13 \\
10.3\end{array}$ & $\begin{array}{l}2.7 \\
2.7\end{array}$ & $\begin{array}{l}0.8 \\
0.5\end{array}$ & $\begin{array}{l}5.9 \\
6.2\end{array}$ & $\begin{array}{l}4.1 \\
3.1\end{array}$ & $\begin{array}{l}1.2 \\
0.7\end{array}$ & $\begin{array}{l}18 \\
17.5\end{array}$ & $\begin{array}{l}3.4 \\
2.7\end{array}$ & $\begin{array}{l}0.7 \\
0.8\end{array}$ & $\begin{array}{l}9.0 \\
9.6\end{array}$ & ns & $* *$ & ns & ns & ns \\
\hline $\begin{array}{l}\text { IgD+ memory cells } \\
\text { reference cell counts } \\
\text { cell counts }\end{array}$ & $\begin{array}{l}1.1 \\
1.0\end{array}$ & $\begin{array}{l}<0.01 \\
0.3\end{array}$ & $\begin{array}{l}2.9 \\
2.1\end{array}$ & $\begin{array}{l}0.3 \\
0.4\end{array}$ & $\begin{array}{l}<0.01 \\
<0.05\end{array}$ & $\begin{array}{l}1.7 \\
1.4\end{array}$ & $\begin{array}{l}0.2 \\
0.2\end{array}$ & $\begin{array}{l}<0.01 \\
<0.05\end{array}$ & $\begin{array}{l}2.4 \\
2.7\end{array}$ & $\begin{array}{l}0.01 \\
0.2\end{array}$ & $\begin{array}{l}<0.01 \\
<0.05\end{array}$ & $\begin{array}{l}1.2 \\
0.8\end{array}$ & $*$ & $* *$ & ns & ns & ns \\
\hline
\end{tabular}




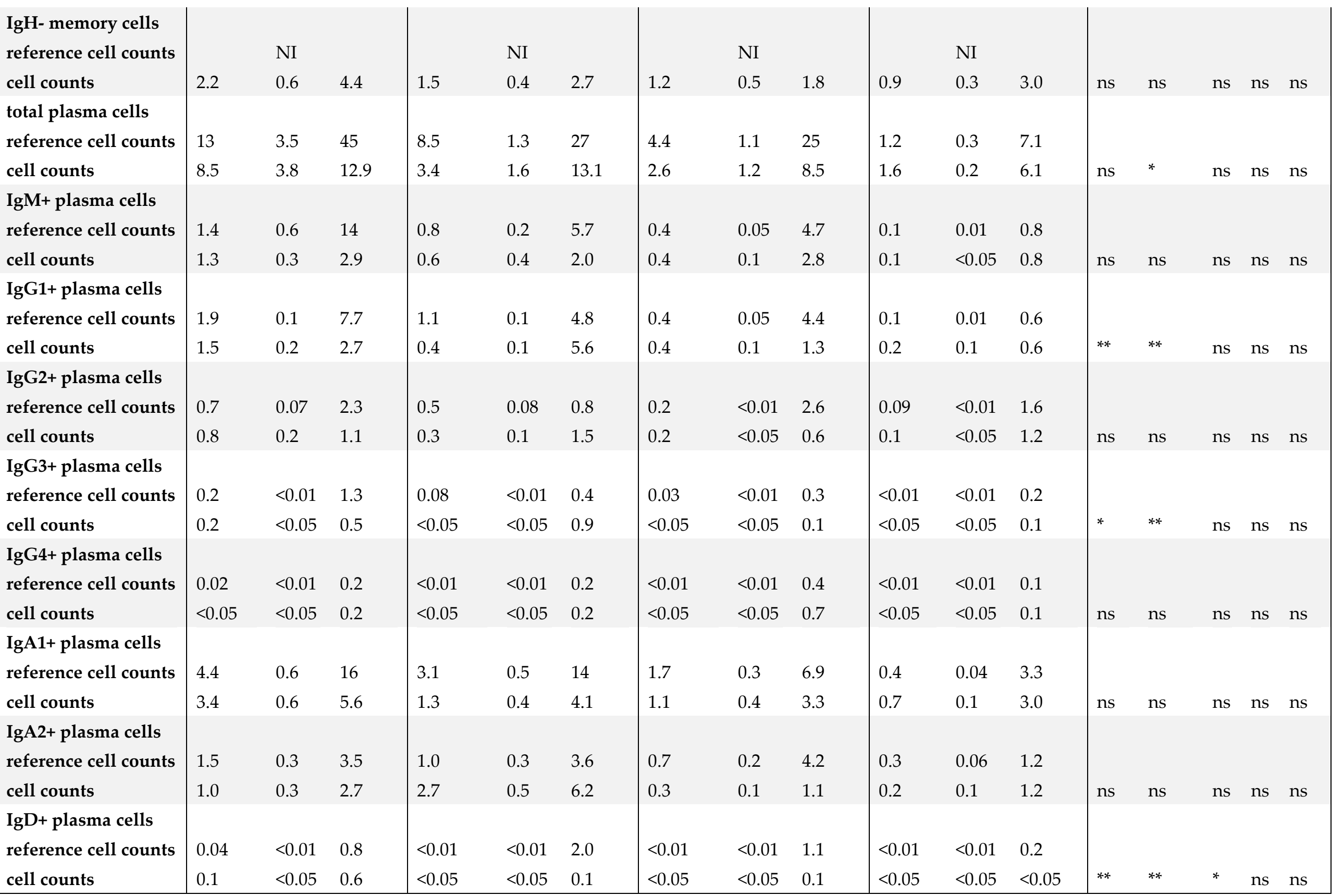




\subsection{Higher counts of naive B cells and plasma cells in children}

B-cell numbers are known to decrease over time from on average 1400 cells $/ \mu$ in children $<2$ years to on average 200 cells $/ \mu \mathrm{l}$ in adults $[32,41]$. This trend was also visible in our data set where children had more B cells than the adult groups (Table 1). This difference was mainly due to high numbers of pre-germinal center (naive) B cells in children. Although memory B-cell numbers were also higher in children than in adults $(160$ cells $/ \mu 1$ in children vs 85.7 cells $/ \mu \mathrm{l}$ in young adults, n.s., and 160 cells/ $\mu \mathrm{l}$ in children vs 63.8 cells/ $\mu \mathrm{l}$ in older adults, $\mathrm{p} \leq 0.01$ ), these differences were less prominent, and mainly restricted to IgG1+ and IgG3+ memory B cells. Finally, several plasma cell subsets were significantly more abundant in children than in adults (IgG1+, IgG3+ and IgD+ plasma cells), but, due to their overall low frequencies, this did not have a major impact on total B-cell numbers. Limited differences in B-cell subset numbers were observed between adolescents and adults (Table 1). These differences were predominantly found in pre-germinal center (naive) B cells and individual plasma cell subsets. Thus, baseline cell numbers of B-cell subsets differed between the cohorts, which was in line with previously published data of age-matched individuals [32].

\subsection{Expansion of plasma cells as the most prominent cellular B-cell change after vaccination}

We have recently shown that administration of an aP booster vaccination in (wP-primed) adults triggers several cellular changes, of which the expansion of (predominantly) IgG1+ plasma cells at day 7 is most prominent [33]. Now, we set out to determine whether the same type of changes occurs in vaccinated individuals, irrespective of age and primary vaccination background.

While total B cells, pre-germinal center B cells and memory B cells remained relatively stable and did not show any consistent fluctuations over time following vaccination, plasma cells in all participants underwent significant expansion between baseline and day 7 ( $\leq \leq 0.01$ for children, and $p \leq 0.001$ for adolescents and the adult cohorts, Figure 1), which returned to baseline at day 14 or day 28 . The magnitude of this expansion was highly similar in children, adolescents and young adults (ratio to baseline: 2.6-3.4) and was significantly higher in older adults as compared to children (ratio: 2.6 in children vs 5.7 in older adults, $\mathrm{p} \leq 0.01$ ). Total plasma cell numbers returned to baseline at day 14 or -if day 14 was not measured- day 28 ( $\mathrm{p} \leq 0.001$ for adolescents, young and older adults, in the children cohort, plasma cell counts were still slightly elevated at day 28). Thus, the expansion of plasma cells 7 days post-vaccination was the most prominent change in all age groups.
10 


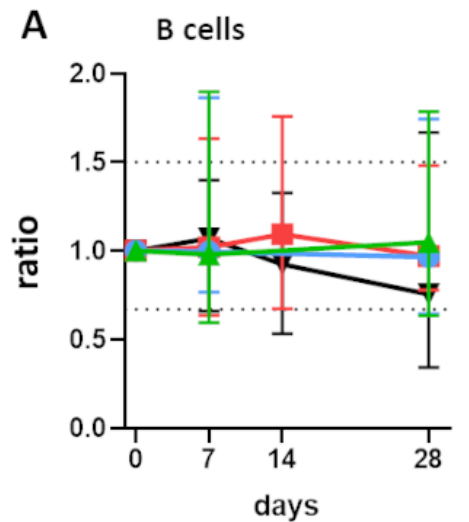

B

B pre-GC B cells

\begin{tabular}{|l|l|}
\hline \multicolumn{2}{|l|}{ Baseline cell counts in cells/ $\mu \mathrm{l}$} \\
\hline Ch & $496.0(346.0-966.0)$ \\
\hline Ad & $430.0(133.0-667.0)$ \\
\hline Yo & $279.0(141.0-481.0)$ \\
\hline Ol & $244.0(53.5-396.0)$ \\
\hline
\end{tabular}

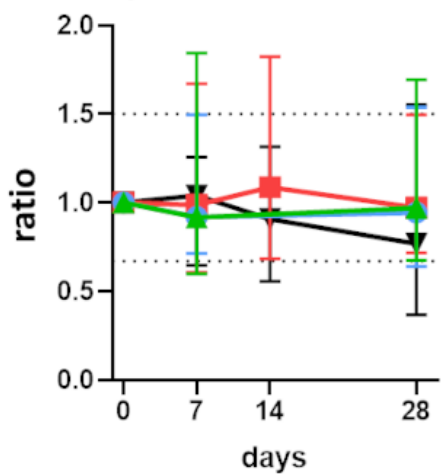

Children (ch)

- Adolescents (ad)

든 Young adults (yo)

* Older adults (ol)

C

memory B cells

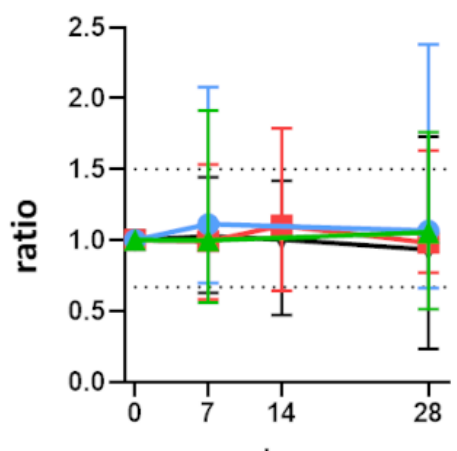

days

\begin{tabular}{|l|l|}
\hline \multicolumn{2}{|l|}{ Baseline cell counts in cells $/ \mu \mathrm{l}$} \\
\hline Ch & $160.0(76.1-252.0)$ \\
\hline Ad & $96.2(33.6-193.0)$ \\
\hline Yo & $85.7(31.3-282.0)$ \\
\hline Ol & $63.8(21.1-171.0)$ \\
\hline
\end{tabular}

\begin{tabular}{|l|l|}
\hline \multicolumn{2}{|l|}{ Baseline cell counts in cells/ $\mu \mathrm{l}$} \\
\hline Ch & $391.0(173.0-731.0)$ \\
\hline Ad & $326.5(96.3-259.0)$ \\
\hline Yo & $194.0(53.1-342.0)$ \\
\hline Ol & $196.0(31.5-273.0)$ \\
\hline
\end{tabular}

D
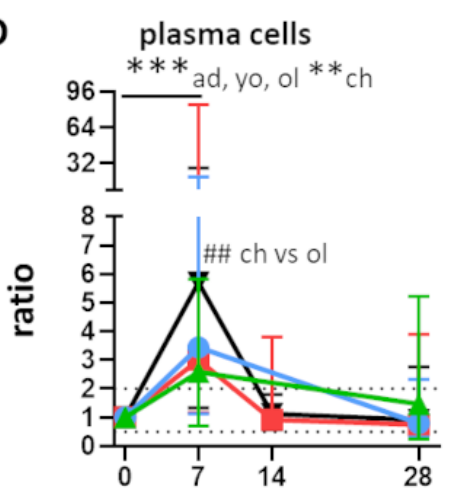

days

\begin{tabular}{|l|l|}
\hline \multicolumn{2}{|l|}{ Baseline cell counts in cells/ $\mu \mathrm{l}$} \\
\hline Ch & $8.5(3.8-12.9)$ \\
\hline Ad & $3.4(1.6-13.1)$ \\
\hline Yo & $2.6(1.2-8.5)$ \\
\hline Ol & $1.6(0.2-6.1)$ \\
\hline
\end{tabular}

Figure 1. Post-vaccination fluctuations of major B-cell subsets. Fluctuations of (a) total B-cells (b) pre-germinal center (pre-GC) B cells, (c) memory B cells and (d) plasma cells post-vaccination, presented as ratio over baseline (median, min-max). For total B cells, pre-GC B cells and memory B cells, the dashed lines indicate a ratio over baseline of 0.67 and 1.5. For plasma cells, the dashed lines indicate a ratio over baseline of 0.5 and 2.0. Underneath each graph, the baseline cell counts per cohort are presented in cells/ $\mu \mathrm{L}$ (median, min-max). To assess longitudinal changes within each cohort, Wilcoxon matched pair signed-ranked test followed by Bonferroni correction was used. To test differences between cohorts at one timepoint, Kruskal-Wallis followed by Dunn's test was used, with exception of the comparison at day 14. At day 14, only blood samples from the adult cohorts were collected. Here, the Mann-Whitney test followed by Bonferroni correction was used. For longitudinal changes, only significant differences compared to baseline are shown. Significant longitudinal differences within a cohort as indicated with ${ }^{*}, \mathrm{p}<0.05 ;{ }^{* *}, \mathrm{p} \leq 0.01 ;{ }^{* *}, \mathrm{p} \leq 0.001$. Significant differences between cohorts at the same time point are indicated with \#, $\mathrm{p}<0.05 ; \# \#, \mathrm{p} \leq 0.01 ; \# \# \#, \mathrm{p} \leq 0.001$. 
Cell expansion at day 7 was not equally pronounced in all plasma cell subsets. It was the most prominent in IgG1+ plasma cells (ratio to baseline: 5.7-17.6, depending on cohort, $\mathrm{p} \leq 0.001$ in all cohorts, with a higher increase in older adults compared to children, $\mathrm{p}<0.05$ ). This was followed by IgG3+ plasma cells (ratio: 3.6-6.5, $\mathrm{p} \leq 0.01$ in children and adolescents, and $p \leq 0.001$ in young and older adults, Figure $2 \mathrm{~A}$ ). IgG4+ plasma cells were significantly increased in children and adolescents (ratio: 5.1 and 7.2 respectively, $\mathrm{p} \leq 0.01$ ). IgG2+ plasma cells were significantly increased in adolescents only (ratio:1.8, $\mathrm{p} \leq 0.001)$. IgA1+ plasma cells were significantly increased in both adult cohorts (ratio: 2.1 and 3.9 in younger and older adults, $\mathrm{p} \leq 0.01$ and $\mathrm{p} \leq 0.001$, respectively). Although IgM+ plasma cells showed a tendency to expand at day 7 in older adults, there was a large variation in-between individuals and the difference was not statistically significant.

Despite individual changes in response patterns between the cohorts, IgG1+ plasma cells were the single most expanded subset. They constituted between $43 \%$ (young adults) and $61 \%$ (adolescents) of all plasma cells at the peak of expansion, while only at most $18 \%$ at baseline (Figure 2B). Moreover, although the ratio (to baseline) of plasma cells was often higher in adults than in children, children had higher baseline IgG1+ plasma cell numbers, and also higher IgG1+ plasma cell numbers at day 7 (median cell count at day 7: 7.64 cells $/ \mu \mathrm{l}$ in children vs 3.81 cells $/ \mu \mathrm{l}$ in older adults, ns). Thus, the expansion of IgG1+ plasma cells was the most prominent in all cohorts. Both an increase over baseline (ratio) and in absolute cell numbers were observed. 
A IgG1+ plasma cells

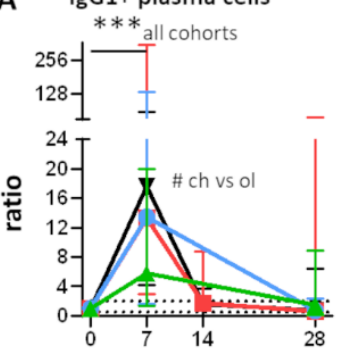

days

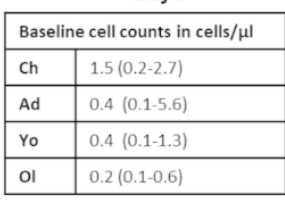

IgM+ plasma cells

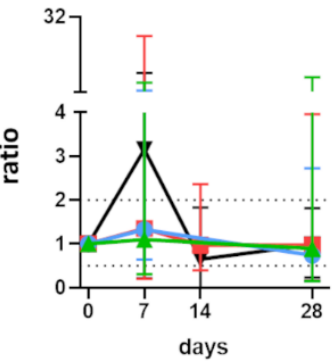

days

\begin{tabular}{|l|l|}
\hline \multicolumn{2}{|c|}{ Baseline cell counts in cells/ $\mu \mathrm{l}$} \\
\hline Ch & $1.3(0.3-2.9)$ \\
\hline Ad & $0.6(0.4-2.0)$ \\
\hline Yo & $0.4(0.1-2.8)$ \\
\hline ol & $0.1(<0.05-0.8)$ \\
\hline
\end{tabular}

B

Children

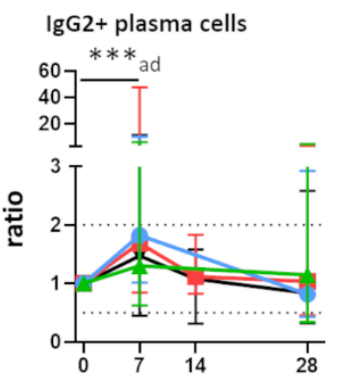

days

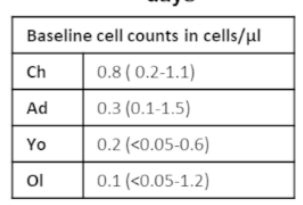

IgA1+ plasma cells
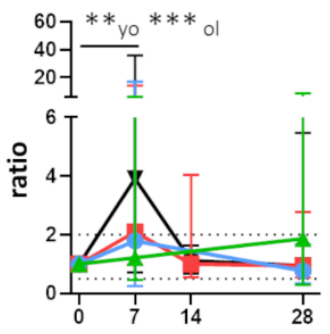

days

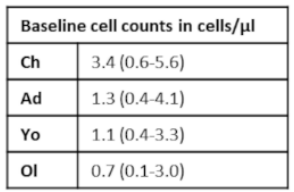

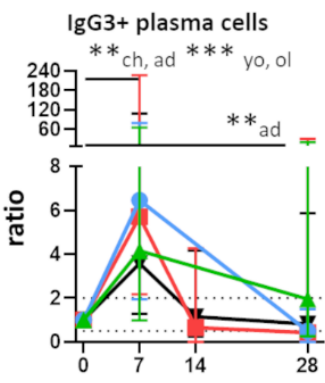

days

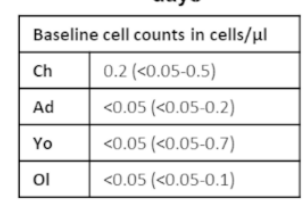

IgA2+ plasma cells

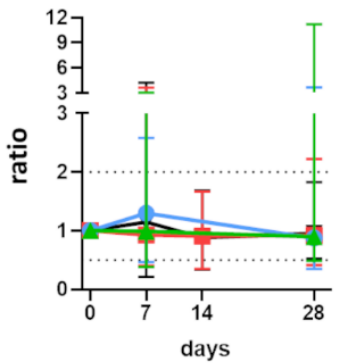

\begin{tabular}{|l|l|}
\hline \multicolumn{2}{|l|}{ Baseline cell counts in cells/ $\mu \mathrm{l}$} \\
\hline Ch & $1.0(0.3-2.7)$ \\
\hline Ad & $2.7(0.5-6.2)$ \\
\hline Yo & $0.3(0.1-1.1)$ \\
\hline ol & $0.7(0.1-1.2)$ \\
\hline
\end{tabular}

Young adults

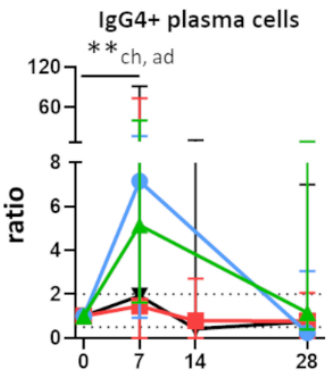

days

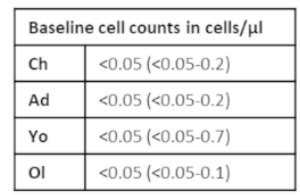

IgD+ plasma cells

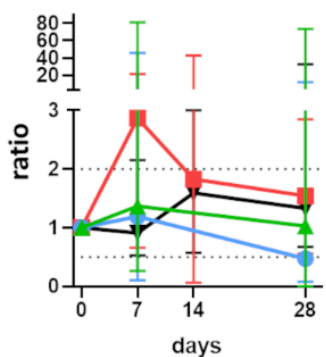

\pm Children (ch)

- Adolescents (ad)

- Young adults (yo)

Older adults (ol)
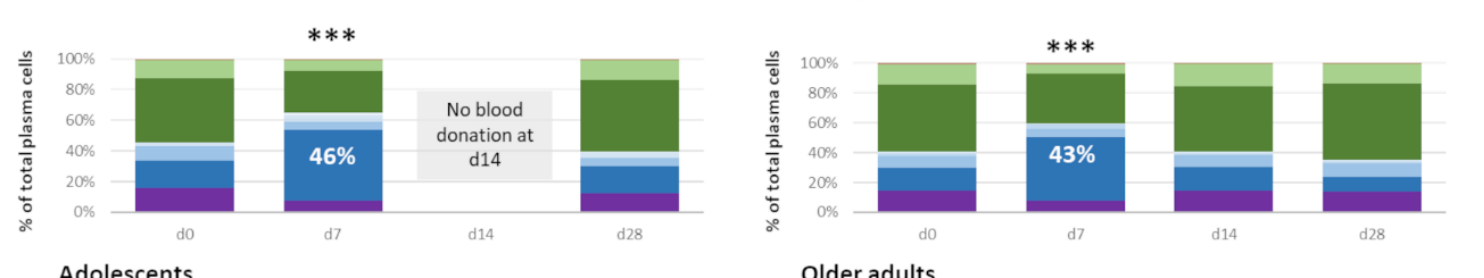

- IgD+ plasma cells

II IgA2+ plasma cells

- IgA1+ plasma cells

IgG4+ plasma cells

- IgG3+ plasma cells

- IgG2+ plasma cells

- IgG1+ plasma cells

- IgM+ plasma cells

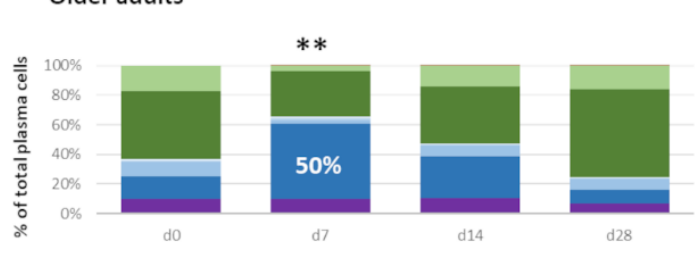

Figure 2. Individuals of all age groups undergo expansion of IgG1+ plasma cells at day 7 post-vaccination. (a) Quantitative changes in plasma cells expressing different Ig subclasses, presented as ratio over baseline (median, min-max). Each dot represents a median value with range. Dashed lines indicate a ratio over baseline of 0.5 and 2 . Underneath each graph, the baseline cell counts per cohort are presented in cells/ $\mu \mathrm{L}$ (median, min-max). Wilcoxon matched pair signed-ranked test followed by Bonferroni correction was used to assess longitudinal differences within each cohort. Differences in ratio at day 7 between cohorts were assessed using Kruskal-Wallis followed by Dunn's test. (b) Over-time distribution of plasma cells expressing different Ig subclasses. Median values for each population were used to construct the plots. Wilcoxon matched pair signedranked test followed by Bonferroni correction was used to assess longitudinal differences in the percentage of IgG1+ cells in the total plasma cell compartment within each cohort. Differences in the percentage of IgG1+ cells in total plasma cell compartment between cohorts were assessed using Kruskal-Wallis followed by Dunn's test, but did not yield significant differences. For pediatric cohorts, no blood samples were collected at day 14. There, the Mann-Whitney test followed by Bonferroni correction was used. For longitudinal changes, only significant differences compared to baseline are shown. Significant longitudinal differences within a cohort as indicated with ${ }^{*}, \mathrm{p}<0.05 ;{ }^{* *}, \mathrm{p} \leq 0.01 ;{ }^{* *}, \mathrm{p} \leq 0.001$. Significant differences between cohorts at the same time point are indicated with \#, $\mathrm{p}<0.05 ; \# \#, \mathrm{p} \leq 0.01 ; \# \# \#, \mathrm{p} \leq 0.001$. $\mathrm{d}=$ days after vaccination. 
Newly generated plasma cells migrate from germinal centers via the blood stream to become long-lived antibody-secreting plasma cells in the bone marrow and other peripheral tissues. Over time, they gradually lose expression of CD20 and gain expression of CD138 [43] (Figure 3A). We used this information to divide plasma cells into consecutive maturation stages and to trace their maturation over time after booster vaccination.

Plasma cells representing all maturation stages were expanded at day 7 (Supplemental Figure 2 for total plasma cells, Figure 3 for IgG1+ plasma cells). This expansion was limited in the least mature CD20+CD138- plasma cells (ratio to baseline: up to 3.1 in IgG1+ plasma cells in children, Figure 3B), more clear in intermediate CD20-CD138- plasma cells (ratio to baseline: up to 22.7 in IgG1+ plasma cells in young adults, in all cohorts $\mathrm{p} \leq 0.01$ or $\mathrm{p} \leq 0.001$ ) and most prominent in the most mature CD20-CD138+ plasma cells (ratio to baseline: up to of 115.6 in young adults, in all cohorts $\mathrm{p} \leq 0.01$ or $\mathrm{p} \leq 0.001$ ). Similar to what was observed for total plasma cells, expansion of IgG1+ plasma cells belonging to different maturation stages was least prominent in children. In all cohorts a significant increase in the percentage of the most mature plasma cells was observed, except for the adolescent cohort, showing just a trend. At day 7 post-vaccination most mature plasma cells constituted between $42 \%$ and $53 \%$ of IgG1+ plasma cells (Figure 3C). Thus, the expansion of plasma cells at day 7 post-vaccination was accompanied by a shift towards a more mature plasma cell phenotype in all cohorts.

95 96 97 98 99

100 101 102 103 104 105 106 107 108 109 110 111 112

As in the adult cohorts an expansion of IgA1+ plasma cells was observed, we evaluated maturation of IgA1+ plasma cells at the peak of expansion as well. In children, no increase in more mature (CD20-CD138- and CD20-CD138+) IgA1+ plasma cells was observed at the peak of expansion. In adolescents, a small increase of most mature (CD20-CD138+) IgA1+ plasma cells was observed, and in both adult cohorts, an increase in both intermediate and most mature (CD20-CD138- and CD20-CD138+) IgA1+ plasma cells was observed at the peak of plasma cell expansion (adolescent cohort: $\mathrm{p}<0.05$, adult cohorts: $\mathrm{p} \leq 0.01$ ). When comparing all cohorts at 7 days post-vaccination, a higher expansion of most mature IgA1+ plasma cells was observed in older adults as compared to children $(\mathrm{p} \leq 0.01)$. Thus, the expansion and maturation of IgA1+ plasma cells seemed to increase with age of the cohort. However, within the oldest cohort, no correlation was found between total IgA plasma cells, IgA1+ plasma cells, or vaccine-specific IgA cells and age. 
A

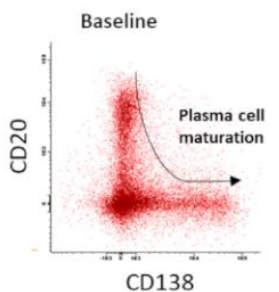

Day 7

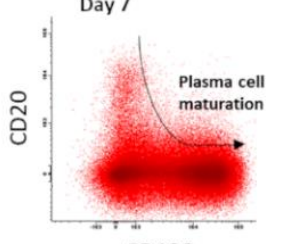

CD138

C

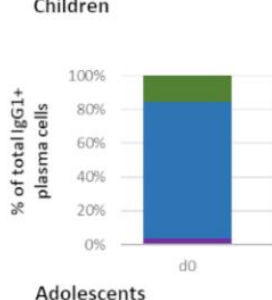

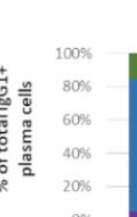

B

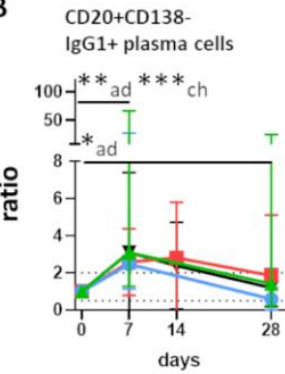

days

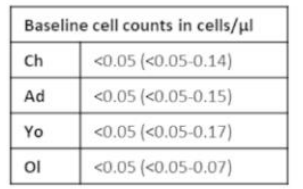

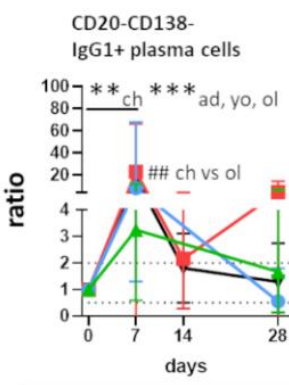

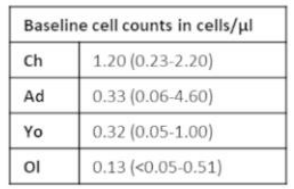

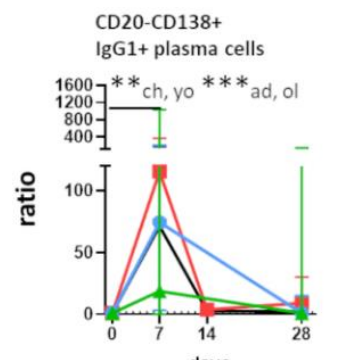

days

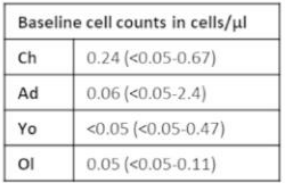

Young adults

\pm Children (ch)

- Adolescents (ad)

- Young adults (yo)

Older adults (ol)

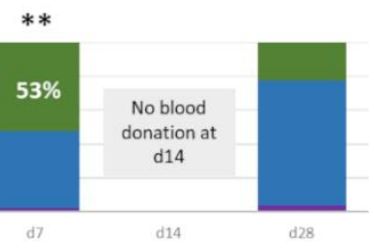

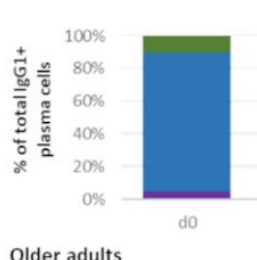

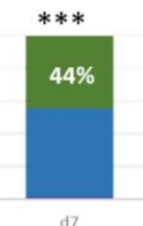

d7

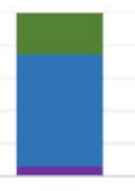

d14

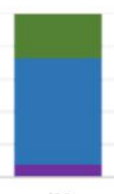

d 28

Older adults

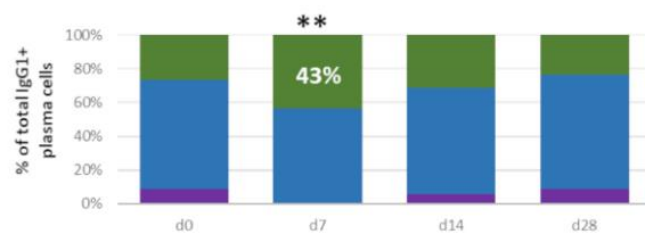

- CD20-CD138+ lgG1+ plasma cells

- CD20-CD138- IgG1+ plasma cells

- CD20+CD138- IgG1+ plasma cells

Figure 3. Over time maturation of IgG1+ plasma cells. (a) Representative dot plots showing the phenotypical changes during plasma cell maturation. The top plot shows a baseline situation, and bottom plot shows a situation at day 7 post-vaccination. Each dot represents an individual cell. The arrow indicates the direction of changes during maturation. (b) Over-time quantitative changes in IgG1+ plasma cells belonging to different maturation stages, presented as ratio over baseline (median, minmax). Dashed lines indicate a ratio over baseline of 0.5 and 2. Underneath each graph, a table shows the baseline cell counts of that population in cells/ $\mu \mathrm{L}$ (median, min-max). (c) Over-time distribution of IgG1+ plasma cells representing different maturation stages with total IgG1+ plasma cells based on expression of CD20 and CD138. Median values for each population were used to construct the plots. Wilcoxon matched pair signed-ranked test followed by Bonferroni correction was used to assess longitudinal differences in percentage of CD20-CD138+ cells in total IgG1+ plasma cells within each cohort. Differences in the percentage CD20-CD138+ cells in total IgG1+ plasma cells between cohorts were assessed using Kruskal-Wallis followed by Dunn's test, but did not yield significant differences. For pediatric cohorts, no blood samples were collected at day 14 . There, the Mann-Whitney test followed by Bonferroni correction was used. For longitudinal changes, only significant differences compared to baseline are shown. Significant longitudinal differences within a cohort as indicated with ${ }^{*}, \mathrm{p}<0.05 ;{ }^{* *}, \mathrm{p} \leq 0.01 ;{ }^{* * *}$, $\mathrm{p} \leq 0.001$. Significant differences between cohorts at the same time point are indicated with $\#, \mathrm{p}<0.05 ; \# \#, \mathrm{p} \leq 0.01 ; \# \#, \mathrm{p} \leq 0.001$. $\mathrm{d}=$ days after vaccination.

\subsection{No clear changes in the memory B-cell compartment over time following vaccination}

While mature antibody-secreting plasma cells predominantly reside in bone marrow and only transiently appear in blood, memory B cells form the circulating component of immunological memory. In the steady state, memory B cells (directed against various antigens) are known to be abundant in blood of both children and adults, and undergo limited quantitative changes following antigen exposure [44, 45]. Still, memory B cells with specific reactivities can be detected in the blood stream [45-47]. In our previous study we have shown that even minor expansions in circulating memory B cells can strongly correlate with a post-vaccination increase in Bp-specific serum Ig levels [33]. Therefore, we set out to determine whether any quantitative changes can be observed at here-selected time points and whether the same pattern is shared by different cohorts. 
Neither total memory B cells nor any of the major memory B-cell subsets underwent consistent quantitative changes over time following vaccination (Figure 4A), with exception of IgG4+ memory B cells in adolescents, which showed a minor but significant increase at day 28 compared to baseline levels. Moreover, at 14 days post-vaccination, there was a minor but significant difference between the number of IgG3+ memory B cells between young and older adults, although there were no significant longitudinal changes within any of the groups. Within each cohort the distribution of memory B-cell subsets was stable over the time of analysis (Figure 4B). However, upon further subdivision of memory B cells based on the expression of CD20, CD21, CD24 and CD27, two memory B-cell subsets underwent significant fluctuations over time (Supplemental Figure 3). In adolescents, there was a significant increase in IgG1+ CD20++CD21-CD24+ memory B cells 28 days after vaccination. Moreover, in adolescents and older adults, there was a significant increase of IgG1+CD20++CD21-CD24-CD27+ memory B cells 14 or 28 days after vaccination as compared to baseline. Therefore, it is possible that memory B cells specific to BoostrixIPV vaccine reside within these CD20++CD21- memory B cells. Here, the use of an antigenspecific approach should lead to additional insights. No significant differences were observed between the cohorts. Although most of subsets defined within IgG1+ memory B cells were significantly more numerous in children than in both adult cohorts (data not shown), this was mainly due to higher numbers of IgG1+ memory B cells in children at baseline. Thus, except for a few minor fluctuations, no differences in the number of memory B cells were observed after Tdap booster vaccination. 

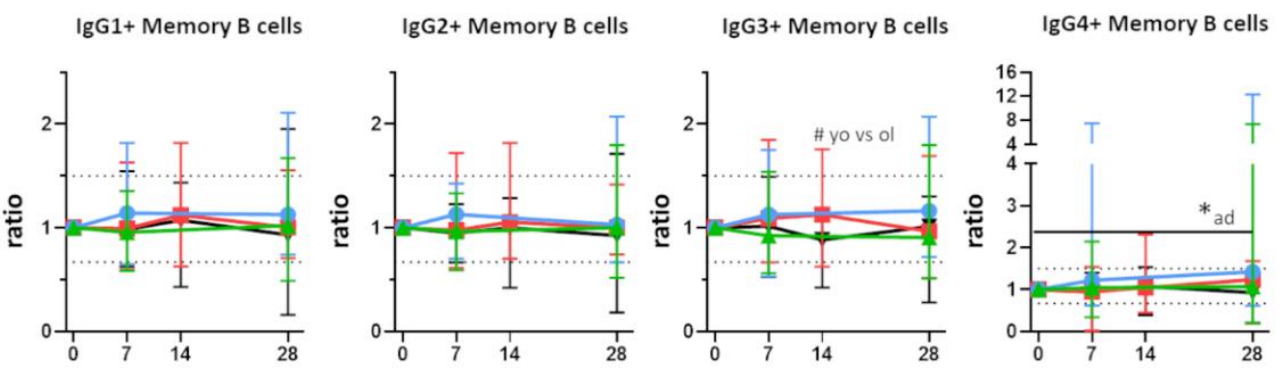

days

\begin{tabular}{|l|l|}
\hline \multicolumn{2}{|l|}{ Baseline cell counts in cells/ $\mu l$} \\
\hline Ch & $47.8(15.2-81.7)$ \\
\hline Ad & $17.3(6.8-44.7)$ \\
\hline Yo & $13.2(5.4-72.5)$ \\
\hline Ol & $16.5(2.8-27.8)$ \\
\hline
\end{tabular}

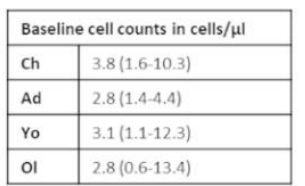

days

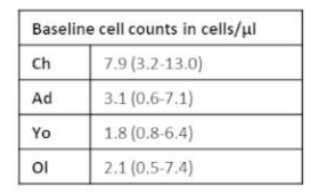

days

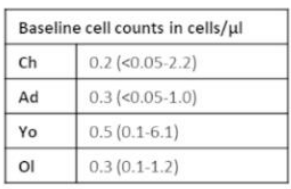

IgA2+ Memory B cells
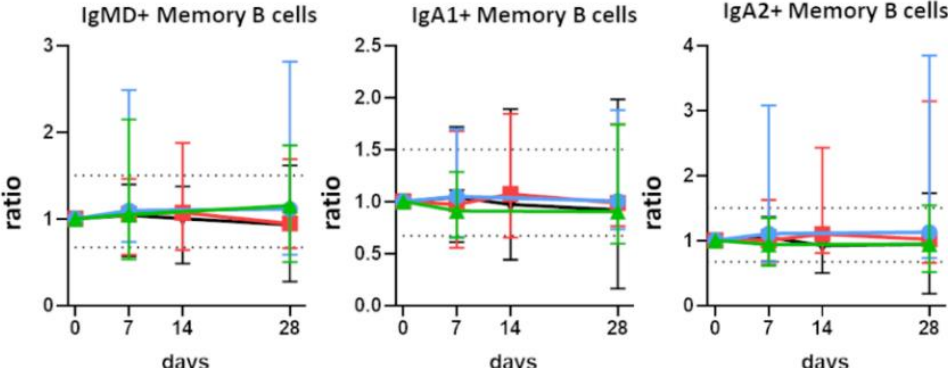

IgD+ Memory B cells

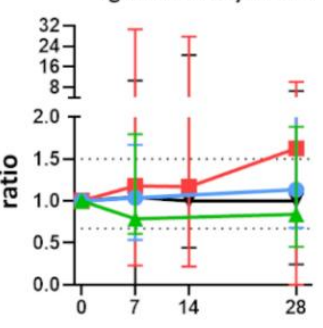

days

\begin{tabular}{|l|l|}
\hline \multicolumn{2}{|c|}{ Baseline cell counts in cells/ $\mu \mathrm{l}$} \\
\hline Ch & $65.7(30.7-129.0)$ \\
\hline Ad & $48.8(16.0-141.0)$ \\
\hline Yo & $37.4(10.0-121.0)$ \\
\hline Ol & $20.8(8.6-93.2)$ \\
\hline
\end{tabular}

\begin{tabular}{|l|l|}
\hline \multicolumn{2}{|l|}{ Baseline cell counts in cells/$/ \mu \mathrm{I}$} \\
\hline Ch & $16.3(6.4-34.7)$ \\
\hline Ad & $11.4(4.4-14.7)$ \\
\hline Yo & $8.0(3.8-42.4)$ \\
\hline Ol & $11.2(4.2-30.4)$ \\
\hline
\end{tabular}

\begin{tabular}{|l|l|}
\hline \multicolumn{2}{|l|}{ Baseline cell counts in cells/ $/ \mathrm{l}$} \\
\hline Ch & $4.8(1.4-10.3)$ \\
\hline Ad & $2.7(0.5-6.2)$ \\
\hline Yo & $3.1(0.7-17.5)$ \\
\hline Ol & $2.7(0.8-9.6)$ \\
\hline
\end{tabular}

days

\begin{tabular}{|l|l|}
\hline \multicolumn{2}{|c|}{ Baseline cell counts in cells/ $/ \mathrm{ll}$} \\
\hline Ch & $1.0(0.3-2.1)$ \\
\hline Ad & $0.4(<0.05-1.4)$ \\
\hline Yo & $0.2(<0.05-2.7)$ \\
\hline ol & $0.2(<0.05-0.8)$ \\
\hline
\end{tabular}

B Children

Young adults

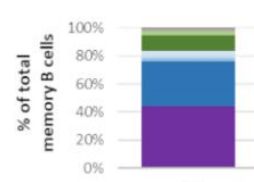

do

Adolescents
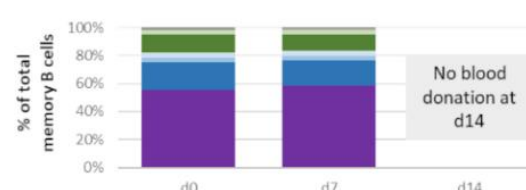

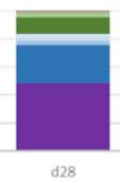

d28

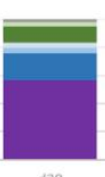

d28

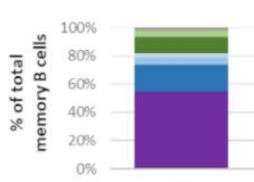

do

Older adults
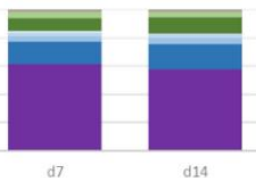

d14

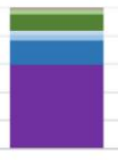

d28

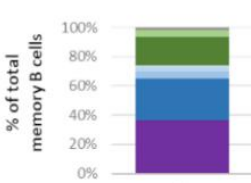

do

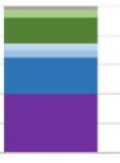

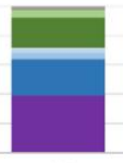

d14

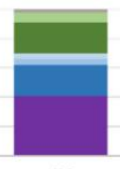

믐 $\mathrm{IgH}+$ memory B cells

a IgD+ memory B cells

In IgA2+ memory B cells

- IgA1+ memory B cells

IgG4+ memory B cells

IgG3+ memory B cells

= IgG2+ memory B cells

- IgG1+ memory B cells

- IgMD+ memory B cells

Figure 4. Stable distribution of memory B-cell subsets over time after vaccination. (a) Quantitative changes in memory B cells expressing different Ig subclasses, presented as ratio over baseline (median, min-max). Dashed lines indicate a ratio over baseline of 0.67 and 1.5. Underneath each graph, a table shows the baseline cell counts of that population in cells/ $\mu \mathrm{L}$ (median, minmax). (b) Over-time distribution of memory B cells expressing different Ig subclasses within the total memory B-cell compartment. Median values for each population were used to construct the plots Wilcoxon matched pair signed-ranked test followed by Bonferroni correction was used to assess longitudinal differences within each cohort. Differences between cohorts were assessed using Kruskal-Wallis followed by Dunn's test, but did not yield significant differences. For pediatric cohorts, no blood samples were collected at day 14. There, the Mann-Whitney test followed by Bonferroni correction was used. For longitudinal changes, only significant differences compared to baseline are shown. Significant differences between cohorts at the same time point are indicated with \#, $\mathrm{p}<0.05 ; \# \#, \mathrm{p} \leq 0.01 ; \# \#, \mathrm{p} \leq 0.001$. $\mathrm{d}=$ days after vaccination. 
3.7 Good correlation between the increase in plasma cell numbers with the vaccine-specific antibody producing cells

185 186

Plasma cells are the main producers of antibodies, and, in a recall response, are mainly generated from Ag-specific memory B cells originating from a previous encounter. To support our flow cytometry-based monitoring of memory B and plasma cell fluctuations, we determined the increase in vaccine-specific plasma and memory B cells via ELISpot.

Most plasma cells induced by vaccination are believed to be Ag-specific; we tested this hypothesis by correlating the flow cytometry data with ELISpot analysis. Indeed, the absolute increase in IgG and IgA plasma cells (as measured by flow cytometry) from baseline to day 7 and the number of vaccine-specific IgG and IgA producing plasma cells (as measured by ELISpot) at day 7 showed a positive correlation (IgG: r= 0.59, p<0.0001; IgA: r=0.60, $\mathrm{p}<0.0001$ ) (Figure 5).

A
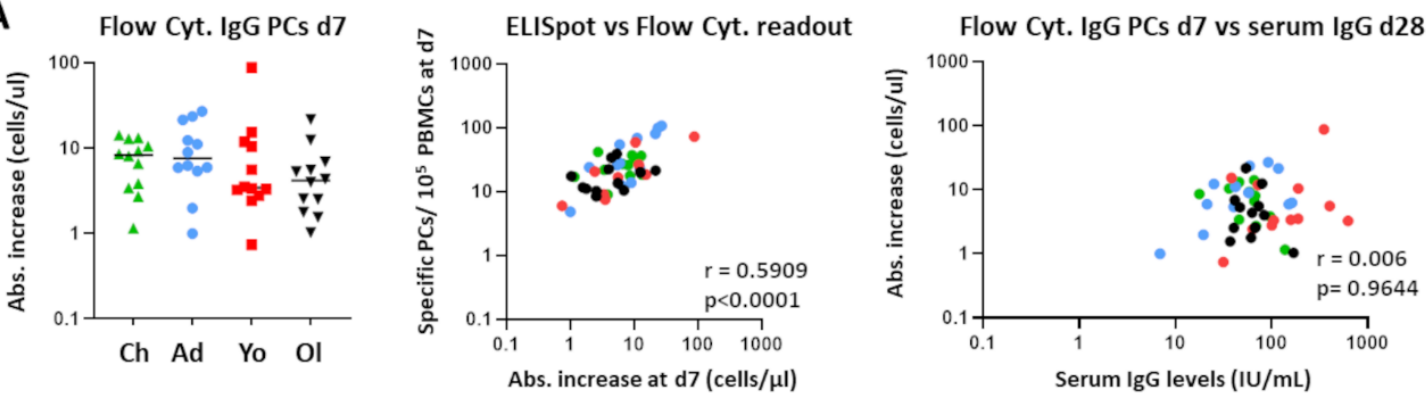

B
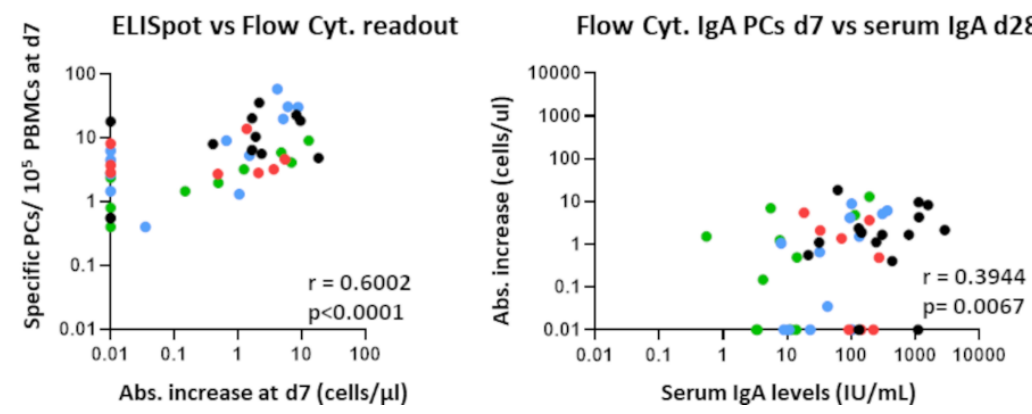

187

188

189

Figure 5. Correlation between cellular changes as measured by flow cytometry and ELISpot, and the correlation between plasma cell expansion and vaccine-specific serum Igs 28 days post-vaccination. (a) Left panel: expansion of IgG+ plasma cells (day 7) per individual, expressed as absolute increase in cells/ul. Middle panel: correlation between the ELISpot and flow cytometry readout for IgG+ plasma cells. Right panel: correlation between the increase in plasma cells (as measured by flow cytometry) and the vaccine-specific serum IgG levels (day 28) (b) Left panel: expansion of IgA1+ plasma cells (day 7) per individual, expressed as absolute increase in cells/ul. Middle panel: correlation between the ELISpot and flow cytometry readout for IgA+ plasma cells. Right panel: correlation between the increase in plasma cells (as measured by flow cytometry) and the vaccine-specific serum IgA levels (day 28). Each dot represents a single donor. Of note; for visualization purposes, all absolute increases lower than 0.01 were set to 0.01 . The original values were used to calculate the Spearman Correlations. Flow Cyt. = flow cytometry; PCs = plasma cells; $d=$ days after vaccination; Abs. = absolute.

Next, we evaluated whether the expansion of circulating IgG+ and IgA+ plasma cells at day 7 could predict the increase in serum IgG and IgA at day 28 and year 1 post-vaccination. We correlated the increase in IgG+ and IgA+ plasma cells (measured by flow cytometry) with the levels of vaccine-specific serum IgG and IgA at day 28 and year 1. Although plasma cells had no predictive value for serum IgG levels, a weak but positive correlation was found for serum IgA levels $(\mathrm{r}=0.3944, \mathrm{p}=0.0067)$. This correlation was lost at 1 -year post-vaccination $(\mathrm{r}=0.3403, \mathrm{p}=0.0207)$.

For memory B cells, no correlation was observed between ELISpot readout and flow cytometry readout (Supplemental Figure 4). Neither flow cytometry IgG nor IgA memory readout correlated with vaccine-specific serum Igs at day 28 or year 1 (data not shown). These findings indicate that for analysis of memory B cells by flow cytometry an Ag- 
specific approach is required. As differences in cellular changes could be found between the different age groups, we also tested for correlations between cell expansion (ratio over baseline) and vaccine specific serum $\mathrm{Ig}(\mathrm{IU} / \mathrm{mL})$ within each age group (Supplemental Figure 5). No correlations between cell expansion and serum Ig levels were found. Thus, the expansion of plasma cells as measured by flow cytometry seems reflective of the numbers of Ag-specific plasma cells, and in this regard flow cytometry and ELISpot can provide complementary data. This is not observed for memory B cells.

3.8 Weak positive correlation between plasma cell expansion and vaccine component-specific IgG levels

As the response to individual vaccine components may differ, we next correlated the IgG1+ and IgA1+ plasma cell expansions at day 7 post-vaccination with the levels of serum IgG and IgA directed against individual pertussis vaccine components. Additionally, we tested whether the degree of maturation correlated with vaccine component-specific IgG or IgA levels. The strongest correlations (with a correlation coefficient between 0.3-0.5) were found between PT- or Prn-specific IgG levels and total IgG1+ plasma cells or CD20CD138- IgG1+ plasma cells (Supplemental Table 4 (IgG) and 5 (IgA)). No correlations were observed between IgG1+ memory B cell expansion and vaccine component-specific serum IgG, nor between the expansion of IgA memory B cells and vaccine component-specific serum IgA.

\subsection{More prominent cellular responses in participants primed with wP vaccine}

Due to the change in the national immunization program at January 1st 2005, all children and 5 out of 12 adolescents were primed with an aP vaccine, while 7 adolescents and all young adults received the Dutch wP vaccine in childhood (presumably, older adults were vaccinated with wP or received no pertussis vaccination during childhood). It has been previously shown that the type of priming can have an impact on both T-cell and antibody responses [16, 18, 22-24]. To study whether cellular B-cell responses can also be affected by the type of priming, while avoiding the effect of age, we first compared both subgroups of adolescents.

Over time changes in total, naive and memory B cells were minor and comparable between wP and aP-primed groups (Figure 6A). In contrast, changes in plasma cells were much more prominent in the group which was primed with the Dutch wP vaccine (ratio to baseline: 4.8 vs 1.5 at day 7 in total plasma cells). From all plasma cells, the differences were the clearest for IgG1+ (ratio: 23.9 vs 4.5 at day 7), IgG3+ (ratio: 19.7 vs 3.7 at day 7) and IgG4+ (ratio: 9.2 vs 3.2 at day 7) plasma cells. Only the difference in IgG1+ plasma cell expansion reached statistical significance $(\mathrm{p} \leq 0.01)$, possibly due to the low number of participants in both groups. Moreover, plasma cell maturation at the peak of expansion was more prominent in wP-primed adolescents in whom most mature CD20-CD138+ plasma cells constituted $46 \%$ of IgG1+ plasma cells in contrast to $39 \%$ in aP-primed adolescents (Figure $6 \mathrm{~A}+\mathrm{B}$ ). Thus, the type of priming background seems to influence the plasma cell response to later booster vaccinations. In our study, the plasma cell response was stronger and more diverse in wP-primed adolescents.

To exclude that differences observed in the adolescent cohort were caused by the different sex distribution between $\mathrm{aP}$ - and $\mathrm{wP}$-primed individuals, we assessed the impact of sex on the cell expansion in the young adult cohort and extrapolated this to the adolescent cohort. The young adult cohort was well sex-balanced and had a homogenous priming background. We evaluated the expansion of total B cells, plasma cells, IgG1-3+ plasma cells, and IgA1+ plasma cells in males and females. No significant differences were observed between male and female responses (Supplemental Figure 6). Therefore, we concluded that the sex imbalance in the adolescent cohort did not influence the plasma cell expansion as found in this study.

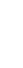

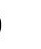

26


The adolescent cohort only consisted of 12 individuals, which is rather small for statistical analysis. Therefore, although we found some age-dependent differences in cellular responses, we next grouped all aP-primed (children and adolescents) and all wP-primed individuals (adolescents, younger and the presumably $\mathrm{wP}$-primed older adults) to increase the size of the study cohorts (Supplemental Figure 7A). Also in this comparison, expansion of total and IgG1+ plasma cells was more pronounced in wP-primed participants. Differences in other plasma cell subsets did not reach statistical significance. Finally, based on ratio to baseline the (total) plasma cell maturation was more prominent in wP-primed individuals as compared to aP-primed individuals, nevertheless the percentage of most mature cells in the IgG1+ plasma cell population did not significantly differ between the two groups (Supplemental Figure 7).

In summary, here we showed that irrespective of the age of vaccinated individuals, the most prominent cellular changes occurred numbers of in circulating plasma cells. Despite some age-related differences, expansion and maturation of IgG1+ plasma cells at day 7 post vaccination is a shared phenomenon. This expansion of plasma cells measured by flow cytometry was complementary to the increase of vaccine-specific plasma cell numbers determined by ELISpot. No correlations between cell expansion and post-vaccination Ag-specific serum Ig levels were observed. Finally, plasma cell responses were stronger in individuals who were $\mathrm{wP}$-primed. 
A

aP-primed adolescents

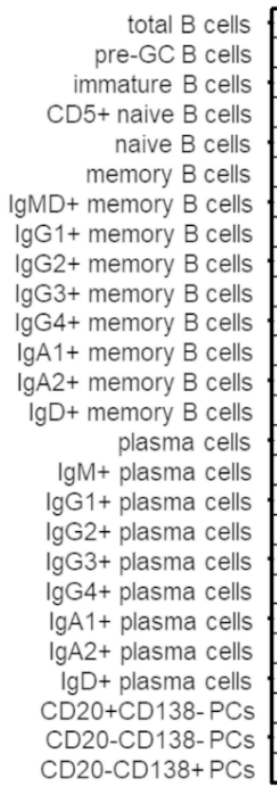

B

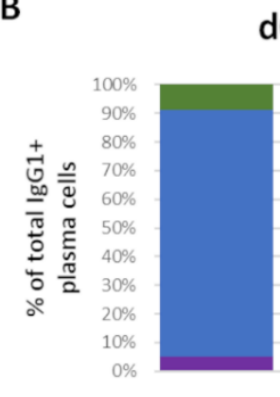

aP

\begin{tabular}{|l|l|l|}
\hline 1.0 & 1.0 & 0.9 \\
\hline 1.0 & 0.9 & 0.9 \\
\hline 1.0 & 0.9 & 1.1 \\
\hline 1.0 & 1.0 & 1.2 \\
\hline 1.0 & 0.8 & 0.8 \\
\hline 1.0 & 1.1 & 1.1 \\
\hline 1.0 & 1.1 & 1.2 \\
\hline 1.0 & 1.1 & 1.1 \\
\hline 1.0 & 1.1 & 1.1 \\
\hline 1.0 & 1.1 & 1.2 \\
\hline 1.0 & 1.0 & 1.3 \\
\hline 1.0 & 1.0 & 1.1 \\
\hline 1.0 & 1.1 & 1.1 \\
\hline 1.0 & 1.2 & 1.0 \\
\hline 1.0 & 1.5 & 0.5 \\
\hline 1.0 & 1.0 & 0.7 \\
\hline 1.0 & 4.5 & 0.2 \\
\hline 1.0 & 1.6 & 1.0 \\
\hline 1.0 & 3.7 & 0.4 \\
\hline 1.0 & 3.2 & 0.2 \\
\hline 1.0 & 1.1 & 0.6 \\
\hline 1.0 & 1.3 & 0.9 \\
\hline 1.0 & 1.2 & 0.3 \\
\hline 1.0 & 1.7 & 1.8 \\
\hline 1.0 & 1.7 & 0.6 \\
\hline 1.0 & 14.0 & 4.6 \\
\hline $\mathrm{d} 0$ & $\mathrm{~d} 7$ & $\mathrm{~d} 28$ \\
\hline & & \\
\hline
\end{tabular}

d0 d7
wP-primed adolescents

\begin{tabular}{|c|c|c|c|c|}
\hline 1.0 & 1.2 & & 1.0 & \\
\hline 1.0 & 0.8 & & 0.7 & \multirow{11}{*}{1.5} \\
\hline 1.0 & 1.1 & & 1.1 & \\
\hline 1.0 & 1.7 & & 1.1 & \\
\hline 1.0 & 0.8 & & 0.7 & \\
\hline 1.0 & 1.0 & & 0.7 & \\
\hline 1.0 & 1.1 & & 0.7 & \\
\hline 1.0 & 0.9 & & 0.8 & \\
\hline 1.0 & 1.0 & & 0.8 & \\
\hline 1.0 & 0.9 & & 0.8 & \\
\hline 1.0 & 1.1 & & 1.0 & \\
\hline 1.0 & 0.9 & & 0.8 & \\
\hline 1.0 & 1.1 & & 0.7 & \\
\hline 1.0 & 0.8 & & 0.8 & \\
\hline 1.0 & 4.8 & * & 0.9 & \\
\hline 1.0 & 1.7 & $*$ & 0.8 & \\
\hline 1.0 & 23.9 & * & 0.5 & \\
\hline 1.0 & 3.7 & $*$ & 0.7 & \\
\hline 1.0 & 19.7 & & 0.5 & \\
\hline 1.0 & 9.2 & & 1.0 & 0.5 \\
\hline 1.0 & 1.9 & & 0.9 & \\
\hline 1.0 & 1.3 & & 0.9 & \\
\hline 1.0 & 1.9 & & 0.7 & \\
\hline 1.0 & 2.3 & $*$ & 1.4 & \\
\hline 1.0 & 4.5 & * & 0.9 & \\
\hline 1.0 & 31.9 & $*$ & 6.5 & ? \\
\hline
\end{tabular}

d28

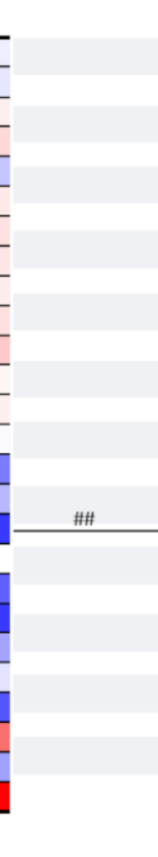

$*$
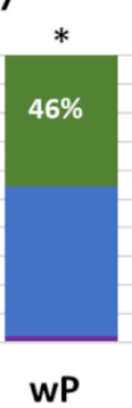

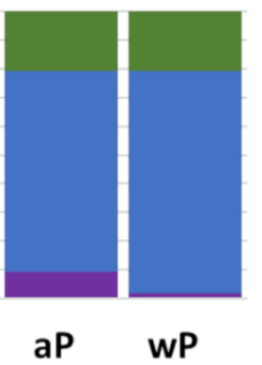

- CD20-CD138+ plasma cells

- CD20-CD138- plasma cells

- CD20+CD138- plasma cells or wP-primed ( $\mathrm{n}=7$ ) adolescents (median values). (b) Over-time distribution of IgG1+ plasma cells representing different maturation stages within total IgG1+ plasma cells. Median values for each population were used to construct the plots. Wilcoxon matched pair signed-ranked test followed by Bonferroni correction was used to assess longitudinal differences in percentage of CD20-CD138+ cells in total IgG1+ plasma cells within each cohort. DifKruskal-Wallis followed by Dunn's test, but did not yield significant differences. For longitudinal changes, only significant differences compared to baseline are shown. Significant longitudinal differences within a cohort as indicated with ${ }^{*}, \mathrm{p}<0.05 ;^{* *}, \mathrm{p} \leq 0.01 ;{ }^{* * *}, \mathrm{p} \leq 0.001$. Significant differences between cohorts at the same time point are indicated with \#, $\mathrm{p}<0.05 ; \# \#, \mathrm{p} \leq 0.01 ; \# \#, \mathrm{p} \leq 0.001$. $\mathrm{d}=$ days after vaccination; $\mathrm{aP}=$ acellular pertussis vaccine; $\mathrm{wP}=$ whole cell pertussis vaccine; pre-GC = pre- Germinal Center.

Figure 6. IgG1+ plasma cell expansion and maturation are more prominent in age-matched participants after wP priming. (a) Heatmap showing over-time changes in memory B-cell and plasma cell subsets in aP-primed ( $\mathrm{n}=5$ ) ferences in the percentage CD20-CD138+ cells in total IgG1+ plasma cells between cohorts were assessed using 
In this study, we applied high-dimensional flow cytometry to investigate changes in B cells in individuals of different ages and priming backgrounds upon administration of an $\mathrm{aP}$ booster vaccine and correlated these findings with vaccine-specific Ig levels in serum. In all age groups expansion and maturation of plasma cells 7 days post-vaccination was the most prominent cellular change. Although in children the expansion of plasma cells was less prominent than in adults, when expressed as ratio to baseline, they had more plasma cells at peak levels due to their initially high plasma cell numbers. Furthermore, cellular responses were stronger in individuals primed with the Dutch wP vaccine than in individuals who were initially primed with aP vaccines. No consistent over-time memory B-cell fluctuations were observed. No direct correlation between plasma cell expansion or memory B-cell expansion with vaccine-specific serum Ig levels was observed. Nevertheless, weak positive correlations were observed between the expansion of $\operatorname{IgG1+}$ plasma cells and Prn- and PT-specific serum IgG levels post-vaccination. Although serology provides insight in Ag-specific Ig levels and function, analysis of circulating immune cells may result in a deeper understanding of the processes induced by the vaccine and the cellular changes preceding Ig production. Our study points at plasma cells as a potential cellular marker of an immune response and contributes to a better understanding of differences in immune responses between age groups and primary vaccination backgrounds.

To ensure objective data analysis, we used the automated gating and identification (AGI) tool in the Infinicyt software, which has been demonstrated to reduce intra- and inter-operator variability and increase reproducibility of the analysis [40, 48-50]. This is especially important for studies with big data from multiple samples, which cannot be analyzed by a single operator within a reasonable timeframe. Irrespective of the new analysis strategy, these data corroborated major findings from our previous study, where data were subjected to manual analysis [33]. This automated analysis approach, in combination with the standardized EuroFlow sample processing and acquisition procedures, allows for identification of fluctuations in small populations of cells e.g. different plasma cell maturation stages.

Levels of Ag-specific serum Igs are routinely used as readout for vaccine efficacy. In many cases a rise in Ag-specific IgG levels is associated with response to vaccination, and for several vaccines, e.g. against rotavirus, an increase in IgA levels has been indicated as correlate of protection [23, 45, 51-53]. As Igs are the product of terminally differentiated B cells (plasma cells), the B-cell compartment may harbor new correlates or biomarkers of ongoing immune responses. Indeed, we found that expansion and maturation of circulating plasma cells 7 days after booster vaccination was the most prominent cellular change. The generation of mainly IgG1+ plasma cells is in line with previous serology-based studies where within Bp-specific serum IgGs mostly IgG1 antibodies were found, with minor contribution of IgG2,-3 and -4 [51,54]. The positive correlation between the numbers of total plasma cells with the vaccine-specific plasma cell numbers supports the assumption that most of the plasma cells at the peak of expansion are vaccine specific.

The observed IgA response, mostly in the adult cohorts, is most likely a result of immunological memory generated by previous (subclinical) infection of the respiratory tract, where a mucosal response against Bp was launched. As Bp circulates within the population, causing outbreaks every 2-5 years, the adult cohorts likely encountered Bp multiple times during life, which explains the more prominent IgA1+ plasma cells response in these groups [55-58]. In contrast, the expansion of IgG4+ plasma cells was mostly seen in the pediatric cohorts, which may be explained by the predominantly aP priming in these cohorts; this has been shown to induce a more Th2-related response as well as increased vaccine-specific serum IgG4 [23, 24].

In addition to the expansion of IgG1+ and IgA1+ plasma cells in adults, and the IgG1+ and IgG4+ response in the pediatric cohorts, which are in line with previous (cellular and serology-based) studies, we also observed a prominent increase in IgG3+ plasma cells in all cohorts $[23,33,51,54]$. A potential explanation for this phenomenon might be that - in 
addition to the memory B cells- there are naive B cells recognizing the antigens and undergo first-step IgG3 class switching and affinity maturation [59].

The difference in plasma cell -and thus antibody- production can have consequences for the type and efficacy of the launched immune response. IgG1 and IgG3 antibodies have stronger opsonizing capacities as compared to IgG4 antibodies [60]. The mixed IgG1IgG3-IgG4 response observed in the mostly aP-primed pediatric cohorts may lead to competition for $\mathrm{Bp}$ antigens in future encounters, possibly leading to less efficient bacterial clearance as compared to the IgG1-IgG3 (and IgA1) response observed in the adult cohorts $[59,61]$. Lastly, the prominent contribution of IgA1+ plasma cells to responses observed in the adult cohorts, which is likely an indicator of previous pertussis encounters, may imply existence of effective mucosal defense mechanisms, and more efficient protection against bacterial translocation in IgA-producing individuals. Comparison of repertoires and reactivities of IgA in mucosa and in circulation could provide better insights into this phenomenon and value of $\operatorname{IgA}$ as a biomarker of protection.

Maturation of plasma cells (total and IgG1+) was observed irrespective of age and priming background. This clear expansion and maturation of total and IgG1+ plasma cells is in line with our previous findings and may be explained by the prolonged retention of newly generated plasma cells in the periphery as well as the competition for bone marrow niches with pre-existing long lived plasma cells [33, 62].

In this study, several differences between the $\mathrm{aP}$ and $\mathrm{wP}$-primed cohorts were observed. Although the size of the age-matched cohort was too limited to reach statistically significant conclusions, major observations were confirmed by analysis of the total cohort, divided based on the priming background. Remarkably, this difference based on priming background was not observed in the overarching part of the BERT study, where the Bpspecific Ig responses of 85 Dutch and Finnish adolescents pre- and post-vaccination were evaluated [29].

The formulation of aP and $\mathrm{wP}$ vaccines differs with regards to number of antigens and the total antigenic load, with $\mathrm{wP}$ vaccines containing the broad variety of pertussis antigens and aP vaccines containing high concentrations of a restricted number of antigens. In consequence, $\mathrm{wP}$ priming is likely to trigger a more diverse antibody response. Since consecutive boosters lead to a more specific, but also more restricted response, this initial broad priming can be beneficial in case of encountering future (mutated) bacterial strains $[10,12,13]$. Interestingly, in this study we showed that, compared to aP-primed individuals, individuals primed with the Dutch $\mathrm{wP}$ vaccine have a stronger response upon aP booster vaccination. It would be of interest to visualize potential differences in breadth of an immune response against Bp antigens. Moreover, since the initial type of priming seems to imprint future responses to given antigens, it should be carefully considered in the design of future vaccines and vaccination strategies. This may also hold true for diseases other than pertussis, such as COVID-19.

To identify unique and shared patterns in-between groups, we primarily focused on normalized data (represented as the ratio to baseline). However, we also showed that, in line with published studies, children had overall higher leukocyte and B-cell counts compared to (older) adults [32,41]. Specifically, the cell count of naive B and T cells -and thus the available naive repertoire- is substantially higher in youth $[32,48]$. Therefore, despite a lower increase in cells expressed as ratio to baseline, children and adolescents may still produce a stronger and more diverse immune responses than adults.

In this study, memory B-cell fluctuations were limited. As the frequencies of Ag-specific memory B cells are low, as demonstrated by previous studies using ELISpot assays, an increase in only these Ag-specific memory B cells may not have an impact on the total memory B-cell population $[63,64]$. Indeed, in this study no correlation was found between the memory B-cell fluctuations measured by flow cytometry and the vaccine-specific memory B cells by ELISpot. However, we observed an increase in CD20++CD21- IgG1+ memory B cells in older adults and adolescents at day 14 and 28 after vaccination, respectively. Interestingly, several studies reported an increased percentage of Ag-specific CD27+CD21-/dim B cells 14 days after influenza vaccination $[65,66]$. There is no 
consensus about the exact function of these CD21-/dim B cells, but, it has been suggested that CD21-/dim B cells are exhausted cells or - as described in autoimmunity and chronic infection- are anergic $[67,68]$. In this context it is not unlikely, that cells which responded to an antigen multiple times would acquire this phenotype. However, Lau and colleagues suggest that CD21-/dim B cells are primed for plasma cell differentiation [65]. Ag-specific flow cytometry studies should give insight into the exact function of this B-cell subset.

No correlation was found between expansion of memory B cells and Ag-specific serum IgG levels at day 28. Previously, we observed a clear correlation between the expansion of IgG1+ memory B cells and the vaccine-specific IgG levels at day 21 in a cohort of 10 healthy adults [33]. Moreover, we found that although in the majority of participants memory B cells showed maximum expansion at 14 days after vaccination, the expansion of memory B cells was not as synchronized in time as the plasma cell expansion, implying that -in some participants- we may not have sampled at the most optimal timepoint [33], especially in the children and adolescent cohorts, where the sampling times were limited to day 0,7 and 28. This difference in timing of memory B-cell responses might be related to the immune status of each individual at baseline and it makes the use of memory B cells as correlates of protection more difficult.

Neither aP nor wP vaccination yields a response that fully mimics natural infection, especially the IgA response seems to be limited upon vaccination and mostly relies upon previous encounters with $\mathrm{Bp}$. To overcome this limitation, multiple novel pertussis vaccines and alternative delivery routes are being developed, such as nasal delivery of a vaccine or the use of life attenuated Bp strains (BPZE1) [69-71]. It would be of interest to evaluate how (cellular) immune responses induced by these vaccine candidates compare to cellular kinetics induced by intramuscular aP and wP vaccines, as well as (controlled) human infection. Such comparison between aP booster vaccination and (controlled) human infection is currently ongoing within the IMI2 PERISCOPE program [72, 73]. These studies will create a solid basis for evaluation of novel vaccination approaches.

Supplementary Materials: The following are available online at www.mdpi.com/xxx/

Supplemental Table 1. Composition of the EuroFlow B-cell panel and technical information on the reagents for the IMI2 PERISCOPE BERT study.

Supplemental Table 2. Phenotypic descriptions used to define B-cell subsets stained with the EuroFlow B-cell panel by manual analysis.

Supplemental Table 3. Baseline distribution of leukocytes, lymphocytes, $\mathrm{T}$ cells and NK cells in donor groups.

Supplemental Table 4. Spearman Ranking Correlation between IgG1+ plasma cell and memory Bcell kinetics and vaccine component-specific serum IgG.

Supplemental Table 5. Spearman Ranking Correlation between IgA1+ plasma cell and IgA memory B-cell kinetics and vaccine component-specific serum IgA.

Supplemental Figure 1. No clear over-time post-vaccination changes in major populations in any of the donor groups. The post-vaccination fluctuations of (A) leukocytes, (B) lymphocytes, (C) T cells, and (D) NK cells, presented as ratio over baseline (median, min-max). Dashed lines indicate a ratio of 0.67 and 1.5 compared to baseline. Underneath each graph, the baseline cell counts per cohort are presented in cells/ $\mu \mathrm{L}$ (median, min-max). To assess longitudinal changes within each cohort, Wilcoxon matched pair signed-rank test followed by Bonferroni correction was used. To test differences between cohorts at one timepoint, Kruskal-Wallis followed by Dunn's test was used, with exception of the comparison at day 14. At day 14, only blood samples from the adult cohorts were collected. Here, the Mann-Whitney test followed by Bonferroni correction was used. For longitudinal changes, only significant differences compared to baseline are shown. ${ }^{*}, \mathrm{p}<0.05 ;{ }^{* *}, \mathrm{p} \leq 0.01$. 
Supplemental Figure 2. Over time maturation of total plasma cells. (A) Representative plots showing the phenotypical changes during plasma cell maturation. Each dot represents an individual cell. The arrow indicates the direction of changes during maturation. (B) Over-time quantitative changes in plasma cells belonging to different maturation stages, presented as ratio over baseline (median, min-max). Dashed lines indicate a ratio of 0.5 and 2.0 compared to baseline. Underneath each graph, the baseline cell counts per cohort are indicated in cells/ $\mu \mathrm{L}$ (median, min-max). (C) Over-time distribution of plasma cells representing different maturation stages within total plasma cells. Median values for each population were used to construct the plots. Wilcoxon matched pair signed-ranked test followed by Bonferroni correction was used to assess longitudinal differences in percentage of CD20-CD138+ cells in total plasma cells within each cohort. Differences in the percentage CD20CD138+ cells in total plasma cells between cohorts were assessed using Kruskal-Wallis followed by Dunn's test, but did not yield significant differences. At day 14, only blood samples from the adult cohorts were collected. Here, the Mann-Whitney test followed by Bonferroni correction was used. For longitudinal changes, only significant differences compared to baseline are shown. Significant longitudinal differences within a cohort as indicated with ${ }^{*}, \mathrm{p}<0.05 ;{ }^{* *}, \mathrm{p} \leq 0.01 ;{ }^{* *}, \mathrm{p} \leq 0.001$. Significant differences between cohorts at the same time point are indicated with \#, $\mathrm{p}<0.05 ; \# \#, \mathrm{p} \leq 0.01 ; \# \#$, $\mathrm{p} \leq 0.001$.

Supplemental Figure 3. No significant changes in IgG1+ memory B-cell subsets upon vaccination. Over-time quantitative changes in IgG1+ memory B-cell subsets, presented as ratio over baseline (median, min-max). Dashed lines indicate a ratio over baseline of 0.67 and 1.5. Underneath each graph, the baseline cell counts per cohort are presented in cells $/ \mu \mathrm{L}$ (median, min-max). Wilcoxon matched pair signed-ranked test followed by Bonferroni correction was used to assess differences in ratio compared to baseline over time. For longitudinal changes, only significant differences compared to baseline are shown. ${ }^{*}, \mathrm{p}<0.05 ;{ }^{* *}, \mathrm{p} \leq 0.01 ;{ }^{* * *}, \mathrm{p} \leq 0.001$.

Supplemental Figure 4. Correlation between cellular changes as measured by flow cytometry and ELISpot. (A) Left panel: expansion of IgG+ Memory B cells (day 28) per individual, expressed as absolute increase in cells/ul. Right panel: correlation between the ELISpot readings and the flow cytometry readout for IgG+ Memory B cells. (B) Left panel: expansion of IgA+ Memory B cells (day 28) per individual, expressed as absolute increase in cells/ul. Right panel: correlation between the ELISpot readings and the flow cytometry readout for IgA+ Memory B cells. Of note; for visualization purposes, all absolute increases lower than 0.01 were set to 0.01 . The original values were used to calculate the Spearman Correlations. Flow Cyt. = flow cytometry; spec.= specific (in this case, specific for the tested vaccine antigens); $\mathrm{MBC}=$ Memory B cells; $\mathrm{PBMC}=$ peripheral blood mononuclear cells; $d=$ days after vaccination; $r=$ Spearman's Correlation coefficient; abs.= absolute.

Supplemental Figure 5. Correlation between cellular changes and the vaccine-specific serum IgG level post-vaccination as determined by Spearman's Ranking Correlation per age cohort. Per cohort the left plot shows the correlation between the maximum expansion of IgG1 plasma cells (day 7) and vaccine-specific serum IgG (directed against FHA, Prn, PT and Tet) (day 28). The right plots show the correlation between the maximum expansion of IgG1 memory B cells (day 14 or day 28) and vaccine-specific serum IgG (directed against FHA, Prn, PT and Tet) (day 28). MBC = memory B cell; $r=$ Spearman's correlation coefficient; $d=$ days after vaccination.

Supplemental Figure 6. Impact of sex on cellular responses after vaccination in the young adult cohort (all wP-primed). Flow cytometry-derived cell numbers (absolute count in cells/ul (A) and ratio over baseline (B)) and their changes over time in an age-matched, wP-primed male $(n=7)$ and female $(n=5)$ cohort. Of note, for one male participant, no baseline B-cell data was available. Therefore, in the graphs showing the ratio over baseline, data of 6 males are shown, whereas absolute counts include the data of 7 males. Graphs indicate median + range. Dashed line indicates ratio of 1.0 (baseline value).

Supplemental Figure 7. IgG1+ and total plasma cell expansion is more prominent in non-agematched donors after $\mathrm{wP}$ priming. (A) Heatmap showing over-time changes in memory B-cell and plasma cell subsets in aP-primed (12 children +5 adolescents) and wP-primed (7 adolescents, 12 young adults and 12 older adults) donors. (B) Over-time distribution of IgG1+ plasma cells representing different maturation stages with total IgG1+ plasma cells. Median values for each population were used to construct the plots. Wilcoxon matched pair signed-ranked test followed by Bonferroni correction was used to assess longitudinal differences in percentage of CD20-CD138+ cells in total IgG1+ plasma cells within each cohort. Differences in the percentage CD20-CD138+ cells in 
total IgG1+ plasma cells between cohorts were assessed using Kruskal-Wallis followed by Dunn's test, but did not yield significant differences. For longitudinal changes, only significant differences compared to baseline are shown. Significant longitudinal differences within a cohort as indicated with ${ }^{*}, \mathrm{p}<0.05 ;{ }^{* *}, \mathrm{p} \leq 0.01 ;{ }^{* * *}, \mathrm{p} \leq 0.001$. Significant differences between cohorts at the same time point are indicated with \#, $\mathrm{p}<0.05 ; \# \#, \mathrm{p} \leq 0.01 ; \# \#, \mathrm{p} \leq 0.001$. $\mathrm{D}=$ days after vaccination; $\mathrm{aP}=$ acellular pertussis vaccine; $\mathrm{wP}=$ whole cell pertussis vaccine.

Author Contributions: Conceptualization, C.T., A.M.B., M.P.A., A.O., G.A.M.B., J.J.M.v.D., and M.A.B.; Methodology, A.T.V., M.P.A., and A.O.; Validation, R.J.G. and B.d.M.; Formal Analysis, A.M.D., P.V., C.T., R.J.G., B.d.M., and M.A.B.; Investigation, A.M.D., P.V., C.T., R.J.G., B.d.M., and M.A.B.; Data Curation, A.M.D., P.V., and G.A.M.B.; Writing - Original Draft Preparation, A.M.D. and M.A.B.; Writing - Review \& Editing, A.M.D., P.V., C.T., R.J.G., B.d.M., A.M.B., A.T.V., M.P.A., A.O., G.A.M.B., J.J.M.v.D., and M.A.B.; Visualization, A.M.D.; Supervision, A.M.B., M.P.A., A.O., G.A.M.B., J.J.M.v.D., and M.A.B.; Project Administration, P.V., A.M.B., G.A.M.B., J.J.M.v.D., and M.A.B.; Funding Acquisition, A.O., G.A.M.B., and J.J.M.v.D.

Funding: This PERISCOPE project has received funding from the Innovative Medicines Initiative 2 Joint Undertaking under grant agreement No 115910. This Joint Undertaking receives support from the European Union's Horizon 2020 research and innovation program and EFPIA and BMGF. The Joint Undertaking is not responsible for any use that may be made of the information this manuscript contains.

Institutional Review Board Statement: The study was conducted according to the guidelines of the Declaration of Helsinki, and approved by the Medical Research Ethics Committees United (MECU, NL60807.100.17-R17.039) on 2017-09-01 and registered at the EU Clinical trial registry (EudraCT number 2016-003678-42).

Informed Consent Statement: Written informed consent was obtained from all subjects (or their parent/guardian) involved in the study.

Data Availability Statement: The data presented in this study are available on request from the corresponding author.

Acknowledgments: The authors would like to thank all research nurses and clinical trial staff, especially J. Zonneveld and G. van Asselts (Spaarne Gasthuis), for their support in sample collection, performing home visits, and management of the clinical data. We also acknowledge dr. M. van Houten (Spaarne Gasthuis) for her help with the trial coordination, clinical trial management and clinical sample collection. We thank P. van Gageldonk, N. Kaagman and L. de Rond from National Institute of Public Health and the Environment for measuring the Ag-specific serum Ig levels and antibody producing cells. We express gratitude to all participants and their families for their participation in this study. Moreover, the authors gratefully acknowledge the Flow cytometry Core Facility at LUMC (coordinated by dr. K. Schepers, M. Hameetman, run by operators S. van de Pas, D. Lowie, J. Jansen, IJ. Reyneveld and former operators E. de Haas and G. de Roo) for their support.

Conflicts of Interest: A.M.D., C.T., M.P.A., A.O., J.J.M.v.D. and M.A.B. report inventorship of the patent "Means and methods for multiparameter cytometry-based leukocyte subsetting" (NL2844751, filing date 5 November 2019) [37], owned by the EuroFlow Consortium. In addition, J.J.M.v.D. and A.O. report to be chairman and co-chairman of the EuroFlow scientific foundation, which receives royalties from licensed patents, which are collectively owned by the participants of the EuroFlow Foundation. These royalties are exclusively used for continuation of the EuroFlow collaboration and sustainability of the EuroFlow consortium. Lastly, J.J.M.v.D. and A.O. report an Educational Services Agreement from BD Biosciences (San José, CA) and a Scientific Advisor Agreement with Cytognos; all related fees and honoraria go to LUMC and USAL, respectively. 


\section{References}

1. Atkinson, W., Epidemiology and prevention of vaccine-preventable diseases. 2006: Department of Health \& Human Services, Centers for Disease Control and ....

2. Cherry, J.D., Historical review of pertussis and the classical vaccine. Journal of Infectious Diseases, 1996. 174(Supplement_3): p. S259-S263.

3. Lambert, L.C., Pertussis vaccine trials in the 1990s. The Journal of infectious diseases, 2014. 209(suppl_1): p. S4-S9.

4. $\quad$ Decker, M.D., et al., Comparison of 13 acellular pertussis vaccines: adverse reactions. Pediatrics, 1995. 96(3): p. 557-566.

5. Rijksvaccinatieprogramma [EN: National Immunization Programme]. 2020 [cited 2020 Nov 18]; official website Dutch Vaccination Programme]. Available from: https://rijksvaccinatieprogramma.nl/english.

6. Tan, T., et al., Pertussis across the globe: recent epidemiologic trends from 2000 to 2013. The Pediatric infectious disease journal, 2015. 34(9): p. e222-e232.

7. Versteegen, P., et al., More than 10 years after introduction of an acellular pertussis vaccine in infancy: a cross-sectional serosurvey of pertussis in the Netherlands. The Lancet Regional Health-Europe, 2021: p. 100196.

8. Heininger, U., et al., Comparative epidemiologic characteristics of pertussis in 10 central and eastern European countries, $2000-2013$. PLoS One, 2016. 11(6): p. e0155949.

9. $\quad$ Berbers, G.A., S.C. de Greeff, and F.R. Mooi, Improving pertussis vaccination. Human vaccines, 2009. 5(7): p. $497-503$.

10. Bart, M.J., et al., Complete genome sequences of 11 Bordetella pertussis strains representing the pandemic ptxP3 lineage. Genome announcements, 2015. 3(6).

11. Mooi, F.R., et al., Bordetella pertussis strains with increased toxin production associated with pertussis resurgence. Emerging infectious diseases, 2009. 15(8): p. 1206.

12. Martin, S.W., et al., Pertactin-negative Bordetella pertussis strains: evidence for a possible selective advantage. Clinical Infectious Diseases, 2015. 60(2): p. 223-227.

13. Lam, C., et al., Rapid increase in pertactin-deficient Bordetella pertussis isolates, Australia. Emerging infectious diseases, 2014. 20(4): p. 626.

14. Sato, Y., M. Kimura, and H. Fukumi, Development of a pertussis component vaccine in Japan. The Lancet, 1984. 323(8369): p. 122126.

15. Gustafsson, L., et al., A controlled trial of a two-component acellular, a five-component acellular, and a whole-cell pertussis vaccine. New England Journal of Medicine, 1996. 334(6): p. 349-356.

16. Liko, J., S.G. Robison, and P.R. Cieslak, Priming with whole-cell versus acellular pertussis vaccine. New England Journal of Medicine, 2013. 368(6): p. 581-582.

17. Klein, N.P., et al., Waning Tdap effectiveness in adolescents. Pediatrics, 2016. 137(3).

18. Sheridan, S.L., et al., Number and order of whole cell pertussis vaccines in infancy and disease protection. Jama, 2012. 308(5): p. 454456.

19. Klein, N.P., et al., Comparative effectiveness of acellular versus whole-cell pertussis vaccines in teenagers. Pediatrics, 2013. 131(6): p. e1716-e1722.

Warfel, J.M., L.I. Zimmerman, and T.J. Merkel, Acellular pertussis vaccines protect against disease but fail to prevent infection and transmission in a nonhuman primate model. Proceedings of the National Academy of Sciences, 2014. 111(2): p. 787-792.

21. Diavatopoulos, D.A., et al., PERISCOPE: road towards effective control of pertussis. The Lancet Infectious Diseases, 2019. 19(5): p. e179-e186.

Lambert, E.E., et al., Uncovering Distinct Primary Vaccination-Dependent Profiles in Human Bordetella Pertussis Specific CD4+ TCell Responses Using a Novel Whole Blood Assay. Vaccines, 2020. 8(2): p. 225. healthy and pertussis infected children. Vaccine, 2011. 29(40): p. 6874-6880. 
24. da Silva Antunes, R., et al., Th1/Th17 polarization persists following whole-cell pertussis vaccination despite repeated acellular boosters. The Journal of clinical investigation, 2018. 128(9): p. 3853-3865.

25. Van Der Lee, S., et al., Whole-cell or acellular pertussis primary immunizations in infancy determines adolescent cellular immune profiles. 2018. 9: p. 51.

26. Kandeil, W., et al., The burden of pertussis in older adults: what is the role of vaccination? A systematic literature review. Expert review of vaccines, 2019. 18(5): p. 439-455.

27. Van Damme, P., et al., Immunogenicity of the reduced-antigen-content dTpa vaccine (Boostrix®) in adults 55 years of age and over: a sub-analysis of four trials. Vaccine, 2011. 29(35): p. 5932-5939.

28. Theeten, H., et al., Primary vaccination of adults with reduced antigen-content diphtheria-tetanus-acellular pertussis or dTpainactivated poliovirus vaccines compared to diphtheria-tetanus-toxoid vaccines. Current medical research and opinion, 2007. 23(11): p. 2729-2739.

29. Versteegen, P., et al., Responses to an acellular pertussis booster vaccination in children, adolescents, and young and older adults: A collaborative study in Finland, the Netherlands, and the United Kingdom. EBioMedicine, 2021. 65: p. 103247.

30. Ellebedy, A.H., et al., Defining antigen-specific plasmablast and memory B cell subsets in human blood after viral infection or vaccination. 2016. 17(10): p. 1226-1234.

31. Wrammert, J., et al., Rapid cloning of high-affinity human monoclonal antibodies against influenza virus. 2008. 453(7195): p. 667671.

32. Blanco, E., et al., Age-associated distribution of normal B-cell and plasma cell subsets in peripheral blood. Journal of Allergy and Clinical Immunology, 2018. 141(6): p. 2208-2219. e16.

33. Diks, A.M., et al., Highly Sensitive Flow Cytometry Allows Monitoring of Changes in Circulating Immune Cells in Blood After Tdap Booster Vaccination. 2021. 12(2091).

34. GlaxoSmithKline. Boostrix Polio; product summary. [Product summary] April 2017 [cited 2020 07-07-2020]; Available from: https://www.geneesmiddeleninformatiebank.nl/Bijsluiters/h35123.pdf.

35. van Gageldonk, P.G., et al., Development and validation of a multiplex immunoassay for the simultaneous determination of serum antibodies to Bordetella pertussis, diphtheria and tetanus. Journal of immunological methods, 2008. 335(1-2): p. 79-89. Buisman, A., et al., Long-term presence of memory B-cells specific for different vaccine components. 2009. 28(1): p. 179-186. van Dongen, J.J.M., et al., Means and methods for multiparameter cytometry-based leukocyte subsetting. 2019, P119646NL00: The Netherlands. p. 111.

38. Kalina, T., et al., Quality assessment program for EuroFlow protocols: Summary results of four-year (2010-2013) quality assurance rounds. Cytometry Part A, 2015. 87(2): p. 145-156.

39. Kalina, T., et al., EuroFlow standardization of flow cytometer instrument settings and immunophenotyping protocols. Leukemia, 2012. 26(9): p. 1986-2010.

40. Pedreira, C., et al., From big flow cytometry datasets to smart diagnostic strategies: The EuroFlow approach. Journal of immunological methods, 2019. 475: p. 112631.

41. Comans-Bitter, W.M., et al., Immunophenotyping of blood lymphocytes in childhoodReference values for lymphocyte subpopulations. The Journal of pediatrics, 1997. 130(3): p. 388-393.

42. Kumar, P. and C. CM, Clinical Medicine, 8th edition. 2012, Edinburgh: Saunders Elsevier. p. 373.

43. Perez-Andres, M., et al., Human peripheral blood B-cell compartments: a crossroad in B-cell traffic. Cytometry Part B: Clinical Cytometry, 2010. 78(S1): p. S47-S60.

44. Tangye, S.G. and D.M. Tarlinton, Memory B cells: Effectors of long-lived immune responses. European journal of immunology, 2009. 39(8): p. 2065-2075.

45. Hendrikx, L.H., et al., Enhanced memory B-cell immune responses after a second acellular pertussis booster vaccination in children 9 years of age. Vaccine, 2011. 30(1): p. 51-58. 
46. Crotty, S., et al., Cutting edge: long-term B cell memory in humans after smallpox vaccination. The Journal of Immunology, 2003. 171(10): p. 4969-4973.

47. Hendrikx, L.H., et al., Identifying long-term memory B-cells in vaccinated children despite waning antibody levels specific for Bordetella pertussis proteins. Vaccine, 2011. 29(7): p. 1431-1437.

48. Botafogo, V., et al., Age Distribution of Multiple Functionally Relevant Subsets of CD4+ T Cells in Human Blood Using a Standardized and Validated 14-Color EuroFlow Immune Monitoring Tube. Frontiers in Immunology, 2020. 11: p. 166.

49. Linskens, E., et al., Improved Standardization of Flow Cytometry Diagnostic Screening of Primary Immunodeficiency by SoftwareBased Automated Gating. Frontiers in Immunology, 2020. 11(2844).

50. Flores-Montero, J., et al., EuroFlow Lymphoid Screening Tube (LST) data base for automated identification of blood lymphocyte subsets. Journal of immunological methods, 2019. 475: p. 112662.

51. Giammanco, A., et al., Analogous IgG subclass response to pertussis toxin in vaccinated children, healthy or affected by whooping cough. Vaccine, 2003. 21(17-18): p. 1924-1931.

52. Vesikari, T., et al., Immunogenicity and safety of the human rotavirus vaccine Rotarix ${ }^{\mathrm{TM}}$ co-administered with routine infant vaccines following the vaccination schedules in Europe. Vaccine, 2010. 28(32): p. 5272-5279.

53. Plotkin, S., et al., General aspects of vaccination, Section 1, Chapter 2. Vaccines. 6th ed. Philadelphia: Saunders Elsevier, 2008: p. 17-36.

54. van der Lee, S., et al., Whole-cell or acellular pertussis vaccination in infancy determines IgG subclass profiles to DTaP booster vaccination. Vaccine, 2018. 36(2): p. 220-226.

55. N. van der Maas, H.d.M., K. Heuvelman, M. van Gent, F.R. Mooi, Kinhoestsurveillance in 2013 en 2014 - RIVM Briefrapport 2014-0165. 2014. p. 36.

56. Cherry, J.D., Epidemic pertussis in 2012 - the resurgence of a vaccine-preventable disease. New England Journal of Medicine, 2012. 367(9): p. 785-787.

Subissi, L., et al., Assessment of IgA anti-PT and IgG anti-ACT reflex testing to improve Bordetella pertussis serodiagnosis in recently vaccinated subjects. Clinical Microbiology and Infection, 2020. 26(5): p. 645. e1-645. e8.

58. Hendrikx, L.H., et al., Serum IgA responses against pertussis proteins in infected and Dutch wP or aP vaccinated children: an additional role in pertussis diagnostics. PLoS One, 2011. 6(11): p. e27681.

59. Diavatopoulos, D.A. and K.M. Edwards, What is wrong with pertussis vaccine immunity? Why immunological memory to pertussis is failing. Cold Spring Harbor Perspectives in Biology, 2017. 9(12): p. a029553.

60. Brüggemann, M., et al., Comparison of the effector functions of human immunoglobulins using a matched set of chimeric antibodies. The Journal of experimental medicine, 1987. 166(5): p. 1351-1361.

61. Weiss, A.A., et al., Acellular pertussis vaccines and complement killing of Bordetella pertussis. Infection and immunity, 2004. 72(12): p. 7346-7351.

62. Odendahl, M., et al., Generation of migratory antigen-specific plasma blasts and mobilization of resident plasma cells in a secondary immune response. Blood, 2005. 105(4): p. 1614-1621.

63. Nanan, R., et al., Acute and long-term effects of booster immunisation on frequencies of antigen-specific memory B-lymphocytes. Vaccine, 2001. 20(3-4): p. 498-504.

64. Buisman, A., et al., Long-term presence of memory B-cells specific for different vaccine components. Vaccine, 2009. 28(1): p. 179-186.

65. Lau, D., et al., Low CD21 expression defines a population of recent germinal center graduates primed for plasma cell differentiation. Science immunology, 2017. 2(7).

66. Koutsakos, M., et al., Circulating TFH cells, serological memory, and tissue compartmentalization shape human influenza-specific B cell immunity. Science translational medicine, 2018. 10(428).

67. Andrews, S.F. and P.C. Wilson, The anergic B cell. Blood, The Journal of the American Society of Hematology, 2010. 115(24): p. $4976-4978$. 
68. Isnardi, I., et al., Complement receptor 2/CD21- human naive B cells contain mostly autoreactive unresponsive clones. Blood, The 702 Journal of the American Society of Hematology, 2010. 115(24): p. 5026-5036.

69. Lin, A., et al., Live attenuated pertussis vaccine BPZE1 induces a broad antibody response in humans. The Journal of Clinical 704 Investigation, 2020. 130(5)

70. Thorstensson, R., et al., A phase I clinical study of a live attenuated Bordetella pertussis vaccine-BPZE1; a single centre, double-blind, placebo-controlled, dose-escalating study of BPZE1 given intranasally to healthy adult male volunteers. PloS one, 2014. 9(1): p. e83449.

71. Boehm, D.T., et al., Intranasal acellular pertussis vaccine provides mucosal immunity and protects mice from Bordetella pertussis. $\quad 708$ NPJ vaccines, 2019. 4(1): p. 1-12. 709

72. De Graaf, H., et al., Investigating Bordetella pertussis colonisation and immunity: protocol for an inpatient controlled human infection model. BMJ open, 2017. 7(10): p. e018594.

73. Preston, A., et al., Controlled human infection with Bordetella pertussis induces asymptomatic, immunising colonisation. Clinical 712 Infectious Diseases, 2019. 